\title{
Temperature Dependences of IR Spectra of Humic Substances of Brown Coal
}

\author{
Dmitry S. Volkov ${ }^{1,2} \mathbb{D}$, Olga B. Rogova ${ }^{2} \mathbb{D}$ and Mikhail A. Proskurnin ${ }^{1, *(D)}$ \\ 1 Department of Chemistry, Lomonosov Moscow State University, Leninskie Gory, 1-3, GSP-1, \\ 119991 Moscow, Russia; dmsvolkov@gmail.com \\ 2 Department of Chemistry and Physical Chemistry of Soils, V.V. Dokuchaev Soil Science Institute, \\ Pyzhevsky per., 7/2, 119017 Moscow, Russia; obrogova@gmail.com \\ * Correspondence: proskurnin@gmail.com
}

check for updates

Citation: Volkov, D.S.; Rogova, O.B.; Proskurnin, M.A. Temperature Dependences of IR Spectra of Humic Substances of Brown Coal. Agronomy 2021, 11, 1822. https://doi.org/ 10.3390/agronomy11091822

Academic Editors: Evgeny Lodygin and Elena Shamrikova

Received: 2 August 2021

Accepted: 9 September 2021

Published: 11 September 2021

Publisher's Note: MDPI stays neutral with regard to jurisdictional claims in published maps and institutional affiliations.

Copyright: (c) 2021 by the authors. Licensee MDPI, Basel, Switzerland. This article is an open access article distributed under the terms and conditions of the Creative Commons Attribution (CC BY) license (https:// creativecommons.org/licenses/by/ $4.0 /)$.
Abstract: The capabilities of temperature-monitored IR spectroscopy for studying the organic matter and mineral composition of humic substances (HS) were tested. Temperature dependences of the mid-IR spectra of humic substances heated in the air in the range $25-215{ }^{\circ} \mathrm{C}(298-488 \mathrm{~K}$, with a step of $2.5^{\circ} \mathrm{C}$ ) — for three commercially available samples isolated from brown coal (leonardite) were performed. The characteristic bands were identified, and their changes in band maxima positions and intensities were compared. From the viewpoint of interpretation of HS components, the spectra were divided into regions of quartz lattice region $\left(800-260 \mathrm{~cm}^{-1}\right)$, quartz overtone region (1270-800 $\left.\mathrm{cm}^{-1}\right)$, humic substance organic matter region $\left(1780-1270 \mathrm{~cm}^{-1}\right)$, quartz combination region (2800-1780 $\left.\mathrm{cm}^{-1}\right), \mathrm{CH}$-speciation region $\left(3100-2800 \mathrm{~cm}^{-1}\right)$, and hydrogen-speciation region (4000-3100 $\mathrm{cm}^{-1}$ ) thus selected to contain the dominating type of bands. For the first time, a reversible change in the frequencies of the band maxima in IR spectra upon heating was observed, which can be interpreted as forming structures with a particular order in the studied humic substances in the dry state. For a single sample, both the band-shift scale and the functional dependence of the various bands on temperature differ significantly. The approach differentiates crystalline quartz bands, amorphous silica, and HSOM/surface groups experiencing a different temperature behavior of the band maxima and their intensities. Band-maximum temperature dependence can be considered more stable to changes in experimental conditions than band maxima at a single temperature, thus providing a more detailed HS structure analysis without HS decomposition or destruction.

Keywords: humic substances; FTIR; infrared spectroscopy; temperature infrared spectra; temperatureinduced evolution of band frequencies

\section{Introduction}

Humic substances (HS) are a predominant species of organic matter in natural (soil and waters) and human-made environments such as sewage and landfills [1-4]. Many studies deal with HS as antibacterial/antiviral, antioxidant, metabolic, immunomodulating, and other medicines [5-7]. Additionally, HS are demanded in various branches of soil science and agronomy: fertilizers, plant growth regulators, and mediators and detoxifiers in the polluted ecosystems [6-11]. HS of various origins-soil, sediments, peat, lignites, brown coal—are relevant resources [1,3] involved in soil [9,12], chemical, and biochemical processes of brown coal treatment [13,14] and biomass treatment [15]. These processes require a large volume of information of HS systems, which requires the development of corresponding analysis and characterization methods.

IR spectroscopy is a developed method to study HS and is used to characterize and assess functional (mainly carboxylic and hydroxylic) groups and whole HS organic matter (HSOM) [16-21]. However, like in many other multicomponent samples, the bands of different HS components and functional groups overlap, and a resulting HS IR spectrum shows a small number of relatively uninformative broad overlapping bands. Thus, despite 
the simplicity and versatility of conventional IR spectroscopy, the information on HS by this method is somewhat limited and usually constrained by qualitative comparison of the functional group composition $[17,18,21-25]$. Nevertheless, with the potential of IR spectroscopy, it is far from being exhausted for HS and can be seriously enhanced using temperature-dependent IR studies.

Changes in the vibrational spectra of solid samples upon heating or cooling provide information on polymorphic transformations, structural phase transitions, intramolecular interactions, and second-order phase transitions. However, even if such changes are absent, temperature-dependent IR spectra may reveal alterations in the band intensities, positions, shape, and width [26]. Structural deformation by pressure or temperature usually results in small changes in interatomic distances, significantly altering molecular and lattice vibrations that can be monitored using FTIR and Raman spectroscopies [27]. In addition, changes in the crystal structure usually shift the molecule center symmetry and may also lead to changes in intermolecular forces and thus band frequencies [28].

According to Hooke's law, the decreased nearest neighbor distances imply larger force constants and higher frequencies. For crystalline forms, lattice potentials are partially anharmonic; the mean interatomic distances and forces depend on the level of vibrational excitation [29]. Thus, transitions between higher levels are less energetic than transitions between lower levels, which causes a redshift of band maxima with temperature and band broadening [29]. As a rule, the stronger the intermolecular interactions, the more significant the shift. Combined internal and external mode bands move faster with temperature [26]. According to Tielens and Allamandola [30], absorption features sharpen with temperature from the crystal lattice thermal shrinkage, but the integrated absorption strength stays approximately constant [31]. The study of the temperature dependences of vibrational spectra provides information on the structure of a solid sample and, on a decrease in temperature, bands hidden or inactive at room temperature may be revealed. Different modes (e.g., stretching versus bending vibrations) in a material may behave differently upon cooldown since they may have different anharmonicity constants and interact with different phonons, which may account for the observed behavior of amorphous magnesium silicates [32].

Thus, the temperature dependence of band parameters in the IR spectrum of a solid has a fundamental nature that is mainly associated with the structural deformation of its crystal lattice. This effect has long been observed and studied in various minerals such as silicates, analogs of interstellar dust forsterite, hydrous silicates at $4 \mathrm{~K}$ and $300 \mathrm{~K}$ [33], and olivine and enstatite at $80 \mathrm{~K}$ and $300 \mathrm{~K}$ [32]. Mennella et al. [34] investigated the absorption coefficient per unit mass for amorphous and crystalline fayalite, crystalline forsterite, and two kinds of disordered carbon grains over the temperature range 24-295 K. They found that the shift magnitude was $1-5 \mathrm{~cm}^{-1}$ at the maxima in the region of $100-500 \mathrm{~cm}^{-1}$. The temperature effects on the IR modes in silicates are mainly due to the contraction of the material structure at low temperatures [34]. The reduced interatomic distance induces a more vital constant and a progressive shift to coupling to higher frequencies. Bowey et al. [35] studied some silicates (olivine, orthopyroxene, clinopyroxene) at $295 \mathrm{~K}$ and $3.5 \mathrm{~K}$. A shift of the bands with temperature was also found. Of particular note is the work by Johnston et al. [36], in which low-temperature FTIR spectra were used in resolving dickite- and nacrite-like features present in the spectra of kaolin clays when cooled to $<30 \mathrm{~K}$. These features were not resolved at room temperature and only partially resolved at liquid nitrogen temperature $(77 \mathrm{~K})$. The room-temperature and low-temperature positions of the $\mathrm{n}(\mathrm{OH})$ bands of kaolinite, dickite, and nacrite were linearly correlated with the interatomic $\mathrm{OH}-\mathrm{O}$ distances; this relationship served for polytype/disorder identification. An increase in the thermal energy of a solid can provide information on the degree of anharmonicity of the interaction potentials of atoms. For example, significant shifts in band positions for a given temperature change indicate a softer, more anharmonic interatomic potential. These types of effects have been studied in temperature-dependent IR bands and width trends in apatite and kaolinite [37]. 
Thus, temperature dependences of IR spectra are essential for many reasons. First, the spectra in different phase states of a substance can be compared, thereby clarifying the role of intermolecular forces. Second, the bandwidth and spectral resolvability are temperature-dependent; hence temperature measurements improve the chemical analysis. Finally, frequency correlations require temperature-dependent band shifts and intensity changes to solve some theoretical problems [38].

For HS, the temperature dependence of IR spectra has hardly been studied, especially in the region where there are no significant molecular structure changes. The early paper [25] studied the moisture effects on IR spectra using a KBr transmission technique. There are studies devoted to the change in the molecular structure of HS during heating to simulate a fire [39]. HS IR spectra are measured upon heating from $325^{\circ} \mathrm{C}$ [40]. Decarboxylation was found as the primary dehydration reaction from 150 to $400{ }^{\circ} \mathrm{C}$, and anhydride was identified in HS from the FT-IR spectra at a higher temperature region, from 200 to $400{ }^{\circ} \mathrm{C}$ [41]. Along with other methods, IR spectra at $20-800{ }^{\circ} \mathrm{C}$ were obtained to study the temperature effects on the stability of soil humic acids with main features only $(\mathrm{OH}$ stretching at $3450 \mathrm{~cm}^{-1}$, methylene bands $\mathrm{C}-\mathrm{H}$ at $2920 \mathrm{~cm}^{-1}$ and $2850 \mathrm{~cm}^{-1}$, the $\mathrm{C}=\mathrm{O}$ stretching vibrations due to carboxylic groups at $1720 \mathrm{~cm}^{-1}$, the band at $1620 \mathrm{~cm}^{-1}$ due to C-C bonds) [42].

This work aims to demonstrate the capabilities of temperature-monitored IR spectroscopy for studying HS structure, both organic matter and mineral component composition. The IR spectra of several HS of leonardite were studied upon continuous heating from 25 to $215^{\circ} \mathrm{C}$; all the experiments (temperature dependence, centrifugation, and matrix assignment) were used previously but never combined.

\section{Materials and Methods}

\subsection{Samples}

Humic acid sodium salt (technical grade, Sigma-Aldrich Inc., St. Louis, MO, USA, CAS Number: 68131-04-4) was used. Malcolm and MacCarthy [43] showed that this HS is similar to leonardite humic acid and Wyoming dopplerite. Other samples are Powhumus (potassium humate) from German leonardite (HUMINTECH, GmbH, Grevenbroich, Germany) and Potassium humate from Sakhalin leonardite. These samples are further referred to as Sigma-Aldrich, Powhumus, and Sakhalin from this point on. Kaolin came from the Polog deposit (Ukraine, 97\% of kaolinite in a purified sample) was used for comparison. The samples were not purified and used in their native state. All the samples were measured in five replicates. Bulk $\mathrm{Si}$ and $\mathrm{Al}$ in the studied samples were previously estimated by ICP-AES [22].

\subsection{FTIR Measurements}

The analysis by IR spectroscopy was carried out on a Vertex 70 IR Fourier spectrometer (Bruker Optik GmbH, Ettlingen, Germany) with a room temperature DLaTGS detector. A GladiATR attachment of a single attenuated total internal reflection (ATR) with a softwarecontrolled diamond crystal heated in the range from room temperature to $215{ }^{\circ} \mathrm{C}$ (Pike Technologies, Madison, WI, USA) was used. The parameters of measurements are summarized in Table 1 . The spectrometer and the attachment were purged with air with a dew point of $-70{ }^{\circ} \mathrm{C}$ (produced by a PG28L Purge Gas Generator, PEAK Scientific, Glasgow, United Kingdom) at a rate of $500 \mathrm{~L} / \mathrm{h}$. The ambient temperature was maintained at $23^{\circ} \mathrm{C}$ with an allowable variation of $\pm 1^{\circ} \mathrm{C}$ using an air conditioner. The post-registration process was performed using OPUS 8.2 software (Bruker Optik GmbH, Ettlingen, Germany). 
Table 1. ATR-FTIR measurement conditions and parameters.

\begin{tabular}{cc}
\hline Spectral range, $\mathrm{cm}^{-1}$ & $4000-400$ \\
Resolution, $\mathrm{cm}^{-1}$ & 2 \\
Background scan & 128 \\
Sample scan & 128 \\
Acquisition mode & 15000 \\
High-frequency limit & $8 \mathrm{~mm}$ \\
Aperture setting & 4 \\
Phase resolution & Double-sided, forward-backward \\
Phase-correction mode & 2 \\
Zero filling factor & Mlackman-Harris 3-term \\
Apodization function & 'Ref' (without amplification) \\
Background signal gain & Auto \\
Sample signal gain & Auto \\
Scanner velocity & $10 \mathrm{kHz}$ \\
Detector & Source \\
Beam splitter & Room temperature DLaTGS \\
Background & MIR, globar \\
& KBr \\
\end{tabular}

Before recording the spectra with heating, an empty ATR crystal spectrum was recorded at $25{ }^{\circ} \mathrm{C}$ as a background. Then, a small amount of the sample was placed on its surface, pressed with a screw, and a program of controlled heating was started at a rate of $0.25^{\circ} \mathrm{C} / \mathrm{min}$ from $25^{\circ} \mathrm{C}$ to $215^{\circ} \mathrm{C}$; spectra registration step is $2.5^{\circ} \mathrm{C}$. After heating to $215{ }^{\circ} \mathrm{C}$, the sample was cooled to $25^{\circ} \mathrm{C}$ in the same manner at a $0.25^{\circ} \mathrm{C} / \mathrm{min}$ rate. The resulting heating and cooling spectra were combined, a corresponding array of spectra of an empty ATR crystal was subtracted from it, an ATR correction was performed, and the maxima positions were determined. The sample was in the ambient atmosphere during the measurement.

Extended ATR correction [44] was performed using the following conditions: ATR crystal diamond, radiation incidence angle 45 degrees, number of ATR reflections, 1 . After ATR correction, a 13-point smoothing procedure was performed. Baseline correction was not performed. Band maxima were determined using the standard band search method using the OPUS software. The standard method is finding the x-position of the interpolated maximum or minimum. The intensity is the corresponding $y$-value of the interpolated maximum or minimum. The sensitivity parameter was $5 \%$ (in some cases $1 \%$ ) to $20 \%$. The higher the threshold is, the fewer bands are displayed.

\section{Results}

The IR spectra of the studied HS samples are shown in Figure 1; more details are given in the Supplementary Materials (Figures S1-S11, see below). The band frequency shifts are visible, discussed below. The spectral series also show a rather complicated and multidirectional change in the signal amplitude, i.e., the total absorbance of the spectral bands; however, in the case of ATR measurements, it depends in a complicated way on the refractive index of the sample and crystal, which also complicatedly depend on temperature and vary nonlinearly. Therefore, the reasonable use of frequency changes and amplitude requires separate measurements beyond this work scope. 


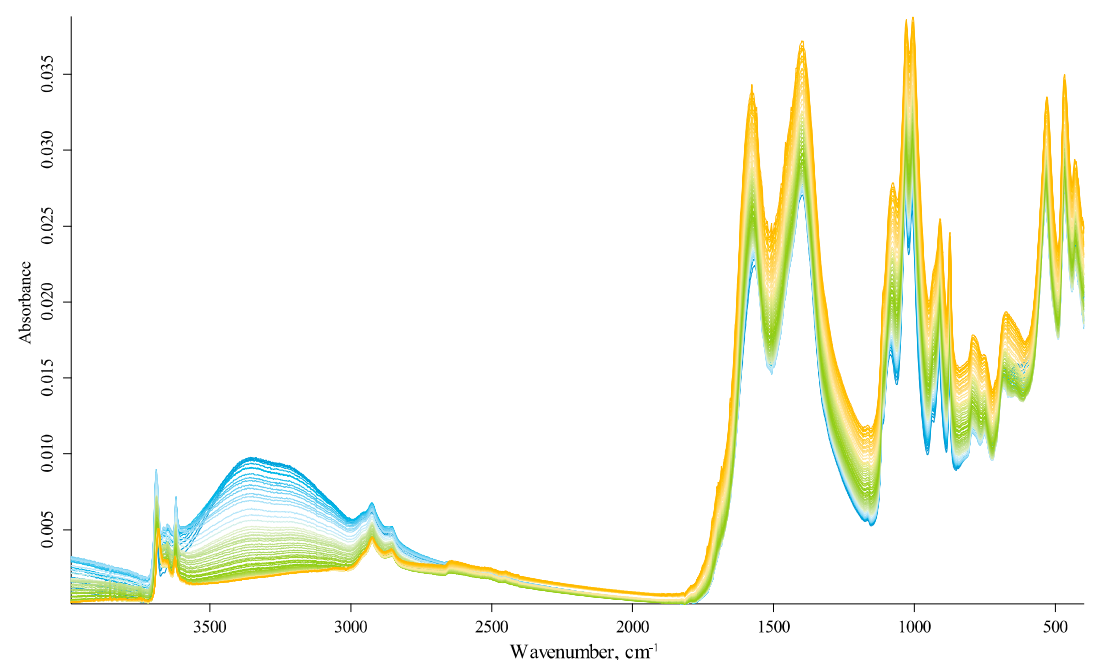

(A)

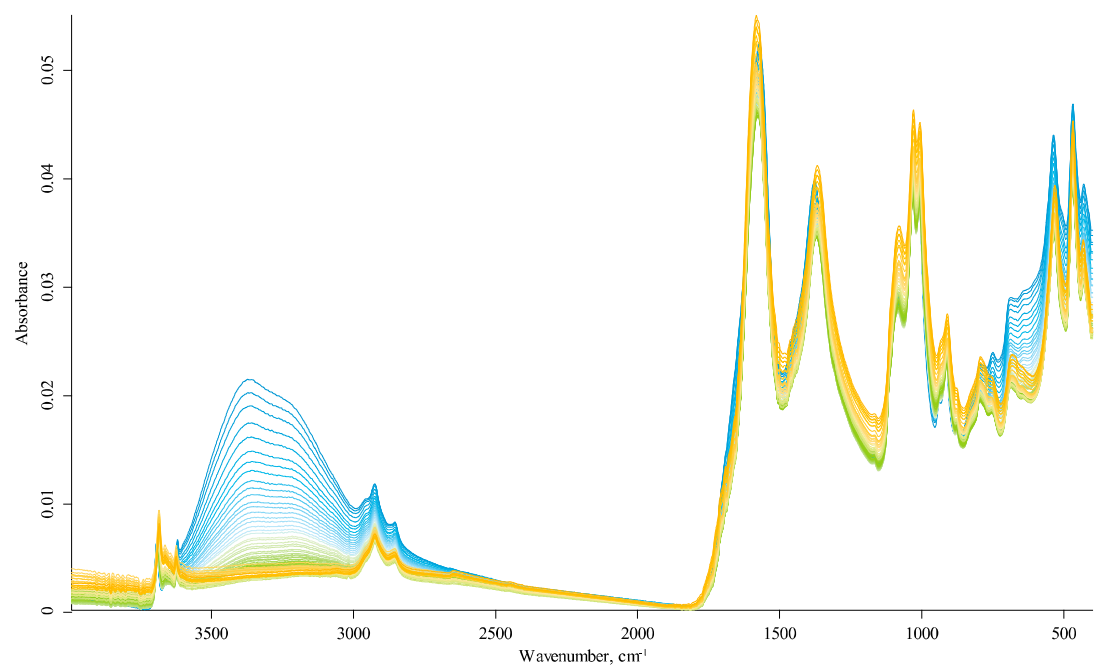

(B)

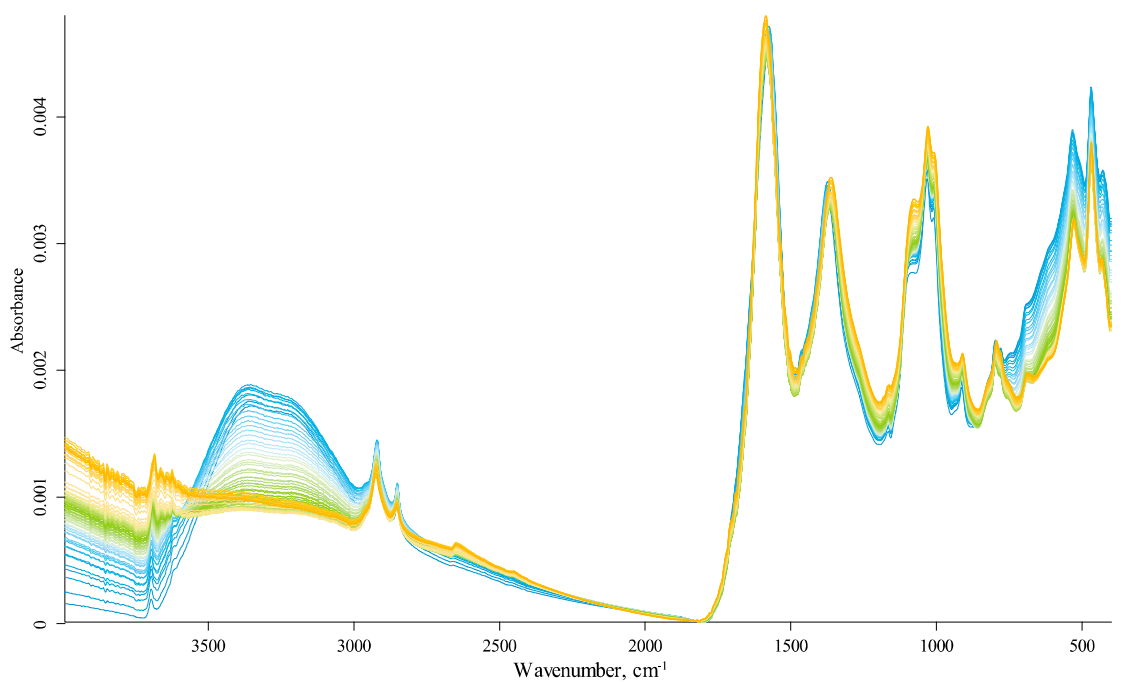

(C)

Figure 1. IR absorption spectra in the range $4000-400 \mathrm{~cm}^{-1}$ after ATR correction of (A) Sigma-Aldrich, (B) Powhumus, and (C) Sakhalin humic substance samples. Temperature increases from 25 to $215^{\circ} \mathrm{C}$ from blue to orange lines. 
To assess the reversibility of the observed changes, we recorded not only the spectra upon heating but also cooling the samples and compared the spectra before heating and after cooling back to $25^{\circ} \mathrm{C}$ (Supplementary Materials, Figures S9-S11). The main differences are water absorption; its content has significantly decreased after the heatingcooling cycle, as expected. The most significant change in all three samples upon heating is the disappearance of the broad band in the region of $2400-3800 \mathrm{~cm}^{-1}$ due to water evaporation. No new bands appeared in the spectra.

Other band-intensity ratios showed insignificant changes during heating and cooling, which indicates the absence or insignificance of changes in the molecular structure of the studied samples. This behavior agrees with thermogravimetric data: dehydration (temperature interval I), from 70 to $110{ }^{\circ} \mathrm{C}$; degradation of aliphatic structures and polysaccharides (interval II), from 210 to $380{ }^{\circ} \mathrm{C}[45,46]$; DSC under oxidative conditions in combination with IR analysis of samples after heating [47,48]; and combinations of TGA, DTA, and DSC [49-51]. Some authors point to the possibility of hydroxyl elimination in the temperature range up to $200{ }^{\circ} \mathrm{C}$ under air conditions for potassium humates extracted from coal $[52,53]$. However, even in this case, the major changes in the HS molecular skeleton begin at significantly higher temperatures. Hoffmann et al. [54] used TGA, DTA, and DSC to study, in particular, a Sigma-Aldrich sample. They noted that the decomposition of polysaccharides, the elimination of functional groups, and the subsequent destruction of phenolic compounds occur in the range of $200-400{ }^{\circ} \mathrm{C}$. Boguta et al. [55] mentioned that the primary process at temperatures below $200^{\circ} \mathrm{C}$ is dehydration. However, a small contribution from the organic-carbon decomposition processes is also possible in the $40-220{ }^{\circ} \mathrm{C}$ range. Thus, it was worth noting that exothermic processes could slightly overlap endothermic effects.

\subsection{Post-Registration Processing of IR Spectra}

The post-registration processing algorithm may considerably change the spectrum. Therefore, all samples were processed in a strictly identical way to minimize the effect of mathematical processing on the results. For clarity, all post-registration processing stages are illustrated with spectra in the Supplementary Materials (Figures S1-S8). The spectra of the samples after processing are shown in the main text.

Extended ATR correction was used. However, since the ATR crystal absorption is close to $100 \%$ in the region $2400-1900 \mathrm{~cm}^{-1}$, this region is significantly noisy (Figure S1, Supplementary Materials). Additionally, it does not contain absorption bands for the studied HS samples. Therefore, this region is replaced by a straight line to apply the extended ATR correction procedure correctly.

The ATR refractive index is determined by the crystal material and the accessory design (the angle and the number of reflections). Additionally, the average refractive index of the sample must be known, and this value, on the one hand, significantly affects the corrected spectrum shape; on the other hand, it is not known precisely for the test sample. There are no data of the sample refractive index used for ATR correction in humic substances in the literature.

For most organic materials, a sample refractive index of ca. 1.5, being a good starting point, is recommended as an ATR-correction base value and generally provides excellent correction performance [44]. Some materials, such as samples rich in amorphous carbon such as high carbon-black rubbers, have higher indices, and a value of 2.0 is recommended for these samples [56]. Thus, it is logical to expect an optimum refractive index for HS between these values. According to the literature, the HS refractive index in the visible region is 1.6 [57], 1.60-1.65 [58], or 1.63-1.70 [59]. Therefore, we varied the sample refractive index for ATR correction in the range of 1.5-2.0 on the example of the Powhumus sample (Supplementary Materials, Figures S3 and S4; the initial spectrum is shown in Figure S2). Figure S2 shows that the corrected spectra at $n=1.5,1.6,1.8$, and 1.9 are identical. At $n=2.0$, the spectrum undergoes significant distortions. At $n=1.7$, the spectrum also differs from other corrections, mainly in the band intensities. Besides, in regions of $4000-3800 \mathrm{~cm}^{-1}$ and 1900-1700 $\mathrm{cm}^{-1}$, where a strong distortion band caused by light scattering is observed, 
a value of 1.7 provides the highest degree of its compensation. Based on these experiments and the literature data, we have chosen $n=1.7$ for the ATR correction of all HS spectra in this study.

The spectrum of kaolinite in the region of $3720-3600 \mathrm{~cm}^{-1}$ recorded under the same conditions and on the same equipment as the HS samples compared with the HS spectra is shown in Supplementary Materials, Figures S5-S8. In this case, the initial ATR spectrum of kaolinite was corrected using two refractive indices, 1.5, which is more justified for this mineral, and 1.7 for a correct comparison with HS spectra. For $n=1.5$, the obtained values of the band maxima at $3691.0,3669.5,3652.3$, and $3620.0 \mathrm{~cm}^{-1}$ coincide entirely with the position of the kaolinite bands at a temperature of $305 \mathrm{~K}$ [36]. For $n=1.7$, the difference is observed only for the first band and produces a shift to $3692.0 \mathrm{~cm}^{-1}$.

All spectra after ATR correction are presented as absorption vs. wavenumber. In this case, the absolute value of absorption in ATR depends on many factors, including the particle size, and is not of fundamental importance. After ATR correction, a smoothing procedure was performed. Such processing turned out to be necessary since small noises and, especially, weak water vapor bands introduced an error in some cases in determining the band maximum and were not cut off by the maximum-finder algorithm. The band maxima were determined before and after the smoothing procedure to assess its effect on the band position and general trends. The fluctuations of the maxima (and, thus, the relative band displacements) decreased significantly upon smoothing, but all the change tendencies were preserved. The temperature dependence of the maximum frequency of bands is nonlinear. Baseline correction was not performed since this operation introduces an additional difficult-to-control distortion in determining the exact maximum position.

\subsection{General Description of IR Spectra}

The exact positions of the maxima, the wavenumber shifts in band maxima caused by heating, and the band assignment are given in Table 2 . It sums up the maxima at $25{ }^{\circ} \mathrm{C}$, shifts when heated to $215^{\circ} \mathrm{C}$, and the difference between maxima at 215 and $25^{\circ} \mathrm{C}$. A positive difference indicates a redshift (towards higher wavenumbers); a negative, a blueshift (towards lower wavenumbers).

Table 2. Position, temperature-induced shifts, and assignment of the absorption bands in IR spectra of HS samples.

\begin{tabular}{|c|c|c|c|c|c|c|c|}
\hline \multicolumn{2}{|c|}{ Sigma-Aldrich } & \multicolumn{2}{|c|}{ Powhumus } & \multicolumn{2}{|c|}{ Sakhalin } & \multirow[b]{2}{*}{ Assignment } & \multirow[b]{2}{*}{ Ref. } \\
\hline$v\left(25^{\circ} \mathrm{C}\right)$ & $\begin{array}{l}v\left(215^{\circ} \mathrm{C}\right)-v \\
\quad\left(25^{\circ} \mathrm{C}\right)\end{array}$ & $v\left(25^{\circ} \mathrm{C}\right)$ & $\begin{array}{l}v\left(215^{\circ} \mathrm{C}\right)-v \\
\left(25^{\circ} \mathrm{C}\right)\end{array}$ & $v\left(25^{\circ} \mathrm{C}\right)$ & $\begin{array}{l}v\left(215^{\circ} \mathrm{C}\right)-v \\
\left(25^{\circ} \mathrm{C}\right)\end{array}$ & & \\
\hline 3691.4 & -9.84 & 3692.8 & -9.61 & 3695.9 & -12.04 & $\begin{array}{l}\text { OH stretching of inner-surface hydroxyl } \\
\text { groups, in-phase vibration with a transition } \\
\text { moment nearly perpendicular to the }(001) \\
\text { plane of kaolinite }\end{array}$ & \multirow{4}{*}[60,61]{} \\
\hline 3666.7 & * & 3666.8 & * & - & - & \multirow{2}{*}{$\begin{array}{l}\text { OH stretching of inner-surface hydroxyl } \\
\text { groups, anti-phase vibration with transition } \\
\text { moment lying in the (001) plane of kaolinite }\end{array}$} & \\
\hline 3650.0 & $*$ & 3651.1 & $*$ & - & - & & \\
\hline 3618.7 & 4.57 & 3618.9 & 5.02 & 3613.3 & 10.63 & OH stretching of inner hydroxyl groups & \\
\hline $2960 * * *$ & $*$ & $2960 * * *$ & $*$ & $2960 * * *$ & $*$ & \multirow{3}{*}{$\begin{array}{l}\text { Asymmetric and symmetric } \mathrm{C}-\mathrm{H} \text { stretching } \\
\text { of aliphatic groups } \mathrm{CH}_{\mathrm{x}}\end{array}$} & \multirow{3}{*}[18,62]{} \\
\hline 2925.7 & -1.59 & 2925.2 & -0.13 & 2919.5 & 4.71 & & \\
\hline 2854.9 & 0.47 & 2854.1 & 1.38 & 2850.7 & 2.60 & & \\
\hline 1569.1 & 8.48 & 1571.2 & 11.15 & 1574.9 & 10.54 & $\begin{array}{l}\text { Aromatic } \mathrm{C}=\mathrm{C} \text { stretching of the phenyl ring, } \\
\mathrm{CO} \text { carboxylate stretching; aromatic } \mathrm{C}=\mathrm{C} \\
\text { skeletal stretching vibrations, } \mathrm{C}=\mathrm{O} \text { of } \\
\text { quinone and / or H-bonded conjugated } \\
\text { ketones; -COO- symmetric stretching }\end{array}$ & [20] \\
\hline 1398.0 & 0.13 & - & - & - & - & $\begin{array}{c}1450-\mathrm{CH} \text { deformation of }-\mathrm{CH}_{3} \text { and }-\mathrm{CH} \\
\text { bending of }-\mathrm{CH} \text {; } \\
1350 \text { symmetric - } \mathrm{COO} \sim \text { stretch and / or }-\mathrm{CH} \\
\text { bending of aliphatics }\end{array}$ & [20] \\
\hline
\end{tabular}


Table 2. Cont

\begin{tabular}{|c|c|c|c|c|c|c|c|}
\hline \multicolumn{2}{|c|}{ Sigma-Aldrich } & \multicolumn{2}{|c|}{ Powhumus } & \multicolumn{2}{|c|}{ Sakhalin } & \multirow[b]{2}{*}{ Assignment } & \multirow[b]{2}{*}{ Ref. } \\
\hline$v\left(25^{\circ} \mathrm{C}\right)$ & $\begin{array}{l}v\left(215^{\circ} \mathrm{C}\right)-v \\
\quad\left(25^{\circ} \mathrm{C}\right)\end{array}$ & $v\left(25^{\circ} \mathrm{C}\right)$ & $\begin{array}{l}v\left(215^{\circ} \mathrm{C}\right)-v \\
\left(25^{\circ} \mathrm{C}\right)\end{array}$ & $v\left(25^{\circ} \mathrm{C}\right)$ & $\begin{array}{l}v\left(215^{\circ} \mathrm{C}\right)-v \\
\left(25^{\circ} \mathrm{C}\right)\end{array}$ & & \\
\hline- & - & 1378.1 & -10.39 & 1375.3 & -12.99 & $\begin{array}{l}\text { A combination band, and is primarily } \\
\text { attributed to } \mathrm{CH} \text { absorption in aliphatics, as } \\
\text { well as to } \mathrm{CO}-\mathrm{CH}_{3} \text { vibrations in } \\
\text { lignin-derived phenols }\end{array}$ & {$[63]$} \\
\hline 1164.5 & * & 1164.5 & * & 1164.5 & * & $\mathrm{C}-\mathrm{OH}$ stretching of aliphatic $\mathrm{O}-\mathrm{H}$ & {$[62]$} \\
\hline $1114^{* *}$ & & $1114^{* *}$ & - & - & - & $\begin{array}{l}\text { Si-O stretching (longitudinal mode) of } \\
\text { kaolinite }\end{array}$ & {$[61]$} \\
\hline 1085.2 & -8.42 & 1089.5 & -9.76 & $* *$ & & $\begin{array}{c}\text { Alcoholic and polysaccharide } \mathrm{CO} \text { stretch } \\
\text { and } \mathrm{OH} \text { deformation; } \mathrm{Si}-\mathrm{OH} \text { bend in silicate } \\
\text { impurities }\end{array}$ & {$[62]$} \\
\hline 1031.5 & -2.64 & 1032.1 & -2.89 & 1032.2 & -3.27 & In-plane Si-O stretching (of kaolinite) & {$[61]$} \\
\hline 1008.4 & -3.17 & 1009.5 & -3.06 & 1010.1 & -1.48 & In-plane Si-O stretching (of kaolinite) & {$[61]$} \\
\hline 937.2 & * & 937.7 & * & $935^{* * *}$ & * & $\begin{array}{l}\text { OH deformation of the inner-surface } \\
\text { hydroxyl group of kaolinite }\end{array}$ & {$[61]$} \\
\hline 912.4 & -3.29 & 913.4 & -3.16 & 912.6 & -2.44 & $\begin{array}{l}\text { OH deformation of inner hydroxyl groups } \\
\text { of kaolinite }\end{array}$ & {$[61]$} \\
\hline 875.0 & -0.80 & 875.9 & 1.03 & & & $\begin{array}{l}\mathrm{Si}-\mathrm{O}^{-} \text {or } \mathrm{Si}-\mathrm{O}-\mathrm{Si} \text { bridge or carbonate, } \\
\text { calcite, or polyaromatic bend vibrations }\end{array}$ & {$[60,64-67]$} \\
\hline 795.7 & -3.38 & 796.4 & -3.02 & 797.5 & -3.46 & Si-O in kaolinite & {$[61]$} \\
\hline $778^{* * *}$ & $*$ & $778^{* * *}$ & $*$ & 778.5 & $*$ & Aromatic $\mathrm{CH}$ out of plane bending & {$[20]$} \\
\hline 749.9 & 2.74 & 749.9 & * & $750 * * *$ & * & Si-O, perpendicular & {$[61]$} \\
\hline 713 & $*$ & - & - & - & - & Al-O vibrations or $\mathrm{C}_{4+}$ alkanes & {$[68,69]$} \\
\hline $690 * *$ & - & $690 * *$ & - & $690 * *$ & & $\mathrm{OH}$ translation in kaolinite & {$[70]$} \\
\hline $640 * * *$ & - & $640 * * *$ & - & - & - & $\mathrm{Si}-\mathrm{O}$ & {$[61]$} \\
\hline 534.9 & -4.52 & 536.2 & -4.94 & 532.6 & -5.06 & Si-O-Al deformation in kaolinite & {$[61,70]$} \\
\hline 466.6 & 0.84 & 468.3 & -0.44 & 468.9 & -0.95 & Si-O bending in kaolinite & {$[70]$} \\
\hline 428.6 & 1.28 & 430.0 & 1.85 & & & Si-O deformation of kaolinite & {$[61]$} \\
\hline
\end{tabular}

* The band intensity is low; when heated, becomes comparable to the noise, making it impossible to register the maxima accurately. ** A relatively intense band with a flat top, impossible to determine the exact position of the maximum. ${ }^{* * *}$ A weakly expressed band on the shoulder of another. - No band (indistinguishable from noise).

The mid-IR region bands commonly associated with characteristic HS and soil attributes drop into three regions: $1200-400 \mathrm{~cm}^{-1}, 2000-1400 \mathrm{~cm}^{-1}$, and $4000-2000 \mathrm{~cm}^{-1}$ [71] corresponding to inorganic soil matrix, organic matter, and hydrogen-bond bands, respectively. In our previous paper [72], we divided the whole mid-IR region for silicate soils in a slightly different way: matrix fingerprint region, $1100-400 \mathrm{~cm}^{-1}$; matrix overtone/combination band region, $2500-1100 \mathrm{~cm}^{-1}$; and OH-region, $4000-2500 \mathrm{~cm}^{-1}$. Both divisions roughly serve the same purpose, but the chemical speciation of various samples shows that the region selection should be more detailed [72].

In this paper, we divided the mid-IR region $4000-260 \mathrm{~cm}^{-1}$ into even in more detailsix regions to divide inorganic components and organic matter. Namely, these regions are the quartz lattice region ( $\left.800-260 \mathrm{~cm}^{-1}\right)$; quartz overtone region $\left(1270-800 \mathrm{~cm}^{-1}\right)$; humic substance organic matter (HSOM) region $\left(1780-1270 \mathrm{~cm}^{-1}\right)$; quartz combination region (2800-1780 $\left.\mathrm{cm}^{-1}\right)$; $\mathrm{CH}$-speciation region (3100-2800 $\left.\mathrm{cm}^{-1}\right)$; and hydrogen-speciation region (4000-3100 $\mathrm{cm}^{-1}$ ). These regions were selected to contain the dominating type of bands and be readily and reproducibly dividable in the same manner for all the similar samples, and although some boundaries (e.g., 1260 and $1780 \mathrm{~cm}^{-1}$ ) may be provisional, they are still generally reliable.

\subsection{Primary Band Assignment}

In the following description, we use the direction from low to high energies (low to high wavenumbers). The dominating calibrations in each region go from fundamental 
matrix vibrations to variable amorphous and organic components and then to speciation due to surface groups and coordination (Figure 1).

In the quartz lattice region (800-260 $\left.\mathrm{cm}^{-1}\right)$, most bands belong to quartz lattice, $797 \mathrm{~cm}^{-1}$, O-Si-O stretch, $697 \mathrm{~cm}^{-1}$ (probably, overtone $\cong 2 \times 398 \mathrm{~cm}^{-1}$ ), $535 \mathrm{~cm}^{-1}$ (probably, overtone $\cong 2 \times 265 \mathrm{~cm}^{-1}$ ), $510 \mathrm{~cm}^{-1}$, Si-O-Si bend; $460 \mathrm{~cm}^{-1}, 450$ (shoulder) $\mathrm{cm}^{-1}$, $430 \mathrm{~cm}^{-1}, 420 \mathrm{~cm}^{-1}$, and $410 \mathrm{~cm}^{-1}, \mathrm{O}-\mathrm{Si}-\mathrm{O}$ bend $[61,70]$. Bands at $750 \mathrm{~cm}^{-1}$ and $455 \mathrm{~cm}^{-1}$ can be attributed to amorphous silica [61]. Broad bands with maxima at $640 \mathrm{~cm}^{-1}$ and $610 \mathrm{~cm}^{-1}$ are probably the manifestations of water librations [73]; they are present in kaolinite and quartz (noisy in the latter case) or AlO bending [68]. Bands at $775 \mathrm{~cm}^{-1}$ and $715 \mathrm{~cm}^{-1}$ are absent in kaolinite spectra. The band at $715 \mathrm{~cm}^{-1}$ cannot be reliably attributed and may manifest in-phase rock vibrations of $\mathrm{AlO}$ vibrations [68] or $\mathrm{C}_{4+}$ alkanes [69]. The band at $775 \mathrm{~cm}^{-1}$ may belong to aromatic $\mathrm{CH}$ out-of-plane bending [20].

The quartz overtone band region $\left(1270-800 \mathrm{~cm}^{-1}\right)$ contains a broad, weak band at $1260 \mathrm{~cm}^{-1}$, which could be a quartz combination band $\left(\cong 460+797 \mathrm{~cm}^{-1}\right)$ or Aryl-O stretching of SOM [74]; broadband at 1120-1070 $\mathrm{cm}^{-1}, \mathrm{O}-\mathrm{Si}-\mathrm{O}$ stretch in crystalline and amorphous $\mathrm{SiO}_{2}$ species; bands at $1035 \mathrm{~cm}^{-1}$ and $1010 \mathrm{~cm}^{-1}$, quartz lattice O-Si-O stretch; $1115 \mathrm{~cm}^{-1}, 937 \mathrm{~cm}^{-1}$, and $915 \mathrm{~cm}^{-1}(\mathrm{OH}$ deformation of inner-surface hydroxyl groups of kaolinite [61]). The latter band is also the manifestation of the $\mathrm{O}-\mathrm{H}$ bend of carboxylic species [61].

Other $\mathrm{SiO}$ vibrations are amorphous $\mathrm{SiO}_{2} \mathrm{O}-\mathrm{Si}-\mathrm{O}$ stretch (not present in quartz); 915-912 $\mathrm{cm}^{-1}$, amorphous silica, probably overtone $\cong 2 \times 460 \mathrm{~cm}^{-1}$ [75] or (O-H bend [76]); $890 \mathrm{~cm}^{-1}$, Si-O ${ }^{-}$[64], Si-O-Si bridge [65], or probably polyaromatic bend vibrations. Weak bands at $855 \mathrm{~cm}^{-1}$ and $845 \mathrm{~cm}^{-1}$ may belong to Al-OH [77]. Comparing the spectra of HS samples with kaolinite spectra in 1270-260 $\mathrm{cm}^{-1}$ (Supplementary Materials, Figures S5-S8) reveals that bands at $1115 \mathrm{~cm}^{-1}, 937 \mathrm{~cm}^{-1}, 915 \mathrm{~cm}^{-1}, 797 \mathrm{~cm}^{-1}, 750 \mathrm{~cm}^{-1}, 697 \mathrm{~cm}^{-1}$, $535 \mathrm{~cm}^{-1}, 460 \mathrm{~cm}^{-1}$, and $430 \mathrm{~cm}^{-1}$ correspond to kaolinite, as well as bands at $1035 \mathrm{~cm}^{-1}$ and $1010 \mathrm{~cm}^{-1}$, although they are displaced more strongly in HS samples than other bands in kaolinite. Bands at $1164 \mathrm{~cm}^{-1}, 1085(1089) \mathrm{cm}^{-1}$, and $875 \mathrm{~cm}^{-1}$ are absent in kaolinite spectra. The $1164 \mathrm{~cm}^{-1}$ band corresponds to $\mathrm{C}-\mathrm{OH}$ stretching of aliphatic $\mathrm{O}-\mathrm{H}, 1085 \mathrm{~cm}^{-1}$, to alcoholic or polysaccharide $\mathrm{C}-\mathrm{O}$ stretch and $\mathrm{O}-\mathrm{H}$ deformation, or an $\mathrm{Si}-\mathrm{OH}$ bend in silicate impurities [62].

Bands at $875 \mathrm{~cm}^{-1}$ and $840 \mathrm{~cm}^{-1}$ (weak shoulder companion of the previous band; in all three samples studied, the intensities of these two bands are correlated) are attributed to silicate species by some authors (Si-O- ${ }^{-}$[64] or Si-O-Si bridge [65]), characteristic of large amounts of defects in crystalline quartz, usually in artificial samples [78-80]. However, these band intensities do not correlate with bulk Si and Al in the studied samples by ICP-AES [22], which may prove that they are not related to silicates and aluminosilicates. Therefore, this band may also be attributed to carbonate [60] or calcite [66], as previously reported for various silica-containing samples. An alternative to this attribution is HSOM, most probably polyaromatic bend vibrations. However, the band at $875 \mathrm{~cm}^{-1}$ is significantly more intense than those attributed to aromatic compounds [67].

In the HSOM region (1780-1270 $\mathrm{cm}^{-1}$ ), the bands at $1730 \mathrm{~cm}^{-1}, 1720 \mathrm{~cm}^{-1}, 1700 \mathrm{~cm}^{-1}$, $1695 \mathrm{~cm}^{-1}, 1685 \mathrm{~cm}^{-1}, 1650 \mathrm{~cm}^{-1}, 1640 \mathrm{~cm}^{-1}, 1620 \mathrm{~cm}^{-1}$, and $1550 \mathrm{~cm}^{-1}$ correspond to an aromatic C-C stretch. Bands at $1750 \mathrm{~cm}^{-1}, 1730 \mathrm{~cm}^{-1}$, and $1720 \mathrm{~cm}^{-1}$ (shoulder) are attributed to carbonyl/carboxyl $\mathrm{C}=\mathrm{O}$ [42]. The band at $1645-1640 \mathrm{~cm}^{-1}$, the shoulder band, is the bend $\left(v_{2}\right)$ of the covalent bonds of liquid absorbed water [81]. The complex, broad band at $1574 / 1569 \mathrm{~cm}^{-1}$ is an antisymmetric carboxylate stretch, with contributions from hydrogen-bonded $\mathrm{SiOH}$... H $\mathrm{H}_{2} \mathrm{O} \mathrm{HO}-\mathrm{H}$ stretch (amorphous) [82-85]. A broad band at $1395 / 1380 \mathrm{~cm}^{-1}$ is the symmetric carboxylate stretch [20]. Other bands are $1470 \mathrm{~cm}^{-1}$, $1450 \mathrm{~cm}^{-1}$ (shoulder), O-H, C-H scissoring, antisymmetric methyl bend $[20,65] ; 1370 \mathrm{~cm}^{-1}$, symmetric methyl bend; and $1310 \mathrm{~cm}^{-1}$ (shoulder), probably carboxyl C-O stretch [20].

In the quartz-combination-band region (2800-1780 $\left.\mathrm{cm}^{-1}\right)$, primary bands are $2650 \mathrm{~cm}^{-1}$, carboxylic O-H stretch [86], and $2430 \mathrm{~cm}^{-1}$, probably, amines. In addition, residual bands of $\mathrm{CO}_{2}$ at $2370 \mathrm{~cm}^{-1}$ and $2350 \mathrm{~cm}^{-1}$ are visible. 
The CH-speciation region (3100-2800 $\left.\mathrm{cm}^{-1}\right)$ is comprised of bands at $3020 \mathrm{~cm}^{-1}$ (3020-3100 $\mathrm{cm}^{-1}$ ), alkene/aromatic sp ${ }^{2}=\mathrm{CH}_{2}$ stretch; $2970 \mathrm{~cm}^{-1}$ and $2880 \mathrm{~cm}^{-1}$, the antisymmetric and symmetric stretch of methyl groups; $2925 \mathrm{~cm}^{-1}$ and $2850 \mathrm{~cm}^{-1}$, the antisymmetric and symmetric stretch of methylene groups [18,62]. Bands of $\mathrm{CH}_{\mathrm{x}}$ groups are on the shoulder of the $\mathrm{OH}$ continuum band. A broad band of $2400-3700 \mathrm{~cm}^{-1}$ with a maximum of about $3370 \mathrm{~cm}^{-1}$ is a signature band of $\mathrm{OH}$ vibrations of water with different hydrogen bonds. Additionally, in this region, vibrations of the $\mathrm{OH}$ group in $-\mathrm{COOH}\left(3400-3200 \mathrm{~cm}^{-1}\right)$ and $-\mathrm{C}-\mathrm{OH}$ are present [16]. Thus, we can consider the bands at $2925 / 2919 \mathrm{~cm}^{-1}, 2854 / 2850 \mathrm{~cm}^{-1}, 1574 / 1569 \mathrm{~cm}^{-1}, 1395 / 1378 \mathrm{~cm}^{-1}, 1164 \mathrm{~cm}^{-1}$, and $1085 / 1089 \mathrm{~cm}^{-1}$ and probably $875 \mathrm{~cm}^{-1}, 775 \mathrm{~cm}^{-1}$, and $715 \mathrm{~cm}^{-1}$ mainly assigned to the organic matter of HS samples.

The hydrogen-speciation region (4000-3100 $\mathrm{cm}^{-1}$ ) shows several bands. The bands at $3665 \mathrm{~cm}^{-1}$ and $3650 \mathrm{~cm}^{-1}$ (Figure 1) are weak in Sigma-Aldrich and Powhumus samples, absent in the Sakhalin spectrum. Although they are identified in the spectra at $25{ }^{\circ} \mathrm{C}$, upon heating, their intensities become comparable to the noise, and it is difficult to determine the exact maximum position. A comparison with kaolinite (Supplementary Materials, Figures S5-S8) shows that all four bands in $3720-3600 \mathrm{~cm}^{-1}$ in the Sigma-Aldrich and Powhumus samples refer to kaolinite fragments; the spectra coincide in the series of bands, the ratio of their intensities, and the maximum wavenumbers. Johnston, Kogel, Bish, Kogure, and Murray [36] showed that a more in-depth study of the structure of these fragments requires cryogenic conditions, which was beyond the scope of this work. In this region, the bands are much more broad and less intense in the Sakhalin spectrum than kaolinite bands, and two of the four bands are visible. Other bands in the hydrogen-speciation region are $3710 \mathrm{~cm}^{-1}$ (unbonded $\mathrm{SiO}-\mathrm{H}$ stretch, tilted (kaolinite, clay) [82]; 3700-3680 $\mathrm{cm}^{-1}$, hydrogen-bonded $\mathrm{SiO}-\mathrm{H} \ldots \mathrm{H}_{2} \mathrm{O}$ stretch (amorphous species); $3665 \mathrm{~cm}^{-1}, 3655 \mathrm{~cm}^{-1}$, $3645 \mathrm{~cm}^{-1}, 3635 \mathrm{~cm}^{-1}$, and $3610 \mathrm{~cm}^{-1}$ non-silicate $\mathrm{OH} ; 3650 \mathrm{~cm}^{-1}$ and $3630 \mathrm{~cm}^{-1}$, isolated $\mathrm{SiO}-\mathrm{H}$ in quartz $[60,61]$; and $3400 \mathrm{~cm}^{-1}$ and $3290 \mathrm{~cm}^{-1}$, condensed-phase antisymmetric and symmetric hydrogen-bond ensembles.

\subsection{Temperature Changes}

As a review of existing data shows, a shift in the frequency of the bands with temperature arises if we exclude the cases of phase transitions or chemical changes when the length of bonds changes, which is usually caused by deformation of the crystal lattice (including deformation due to a temperature change) [26-31]. As a multicomponent mixture, HS does not form a crystal lattice, which is consistent with the X-ray diffraction spectra, in which there are no HS reflections. HS is predominantly in solid form under natural conditions and is associated with clay minerals [87]. Thus, the behavior of HS either indicates the formation of local structured fragments, which nevertheless are not found in the XRD spectra, or remnants of mineral fragments, the bands of which are hidden by broad bands of HS. The situation is complicated by the lack of a theoretical model, even for simple crystalline phases, which would make it possible to predict such a frequency shift or relate it to the lattice parameters. The work by Bronnikov et al. [88] deserves special attention. Several polymers were studied, and a change (decrease) in the band frequency is interpreted as stretching of the macromolecule skeleton (an increase in the $\mathrm{C}-\mathrm{C}-\mathrm{C}$ bond angles and the lengths of the valence bonds in the skeleton). The magnitude of the band displacement is related to the relative thermal elongation of the skeleton.

Thus, with a high degree of confidence, temperature-induced changes in the frequency position in the HS spectra indicate the presence of ordered fragments in which phonon vibrations can arise.

\subsubsection{Quartz Lattice Region $\left(800-260 \mathrm{~cm}^{-1}\right)$}

Most bands in this region are fundamental lattice vibrations of quartz and other structured components of the inorganic matrix. The lattice bend vibrations of Si-O-Si $\left(510 \mathrm{~cm}^{-1}\right)$ and $\mathrm{O}-\mathrm{Si}-\mathrm{O}\left(460 \mathrm{~cm}^{-1}, 450 \mathrm{~cm}^{-1}\right.$, and $\left.430 \mathrm{~cm}^{-1}\right)$ do not show any shifts 
(Figure 2) following their behavior of first-order fundamental vibrations [89]. On the contrary, lattice O-Si-O stretch vibrations at $797 \mathrm{~cm}^{-1}$ (Figure 3) exhibit a redshift of $3 \mathrm{~cm}^{-1}$, smaller than shifts of $1-2 \mathrm{~cm}^{-1}$ of bands in the region $1250-800 \mathrm{~cm}^{-1}$.
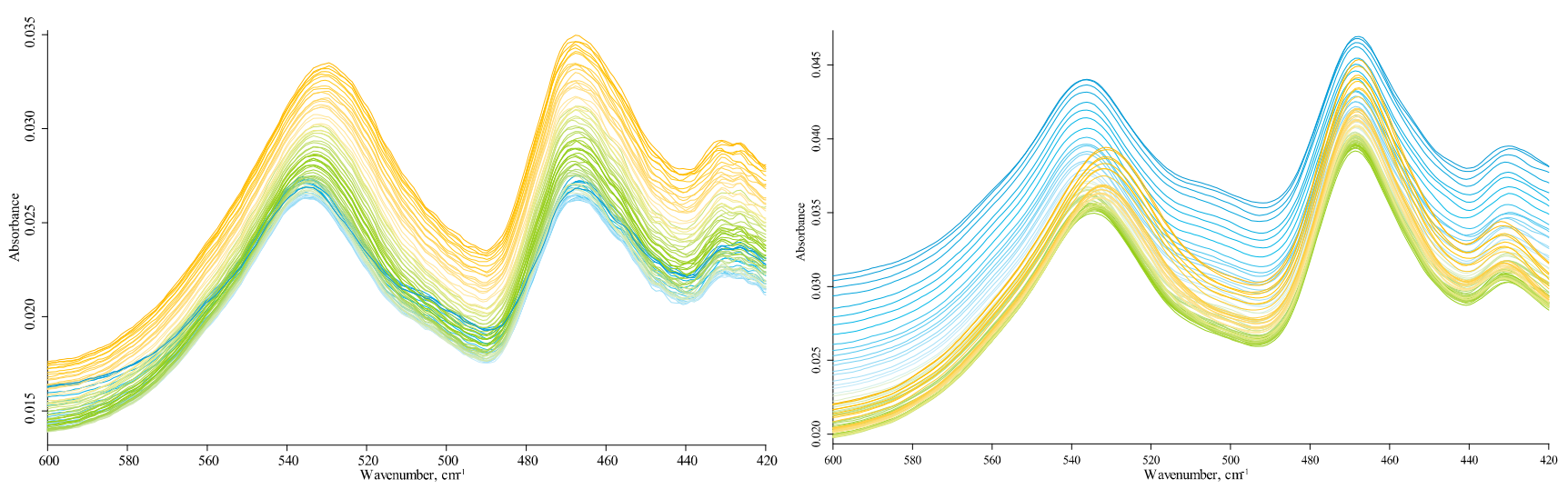

Figure 2. IR absorption spectra in the region $600-420 \mathrm{~cm}^{-1}$ after ATR correction of Sigma-Aldrich (left) and Powhumus (right) without centrifugation. Temperature increases from 25 to $215^{\circ} \mathrm{C}$ from blue to orange lines.
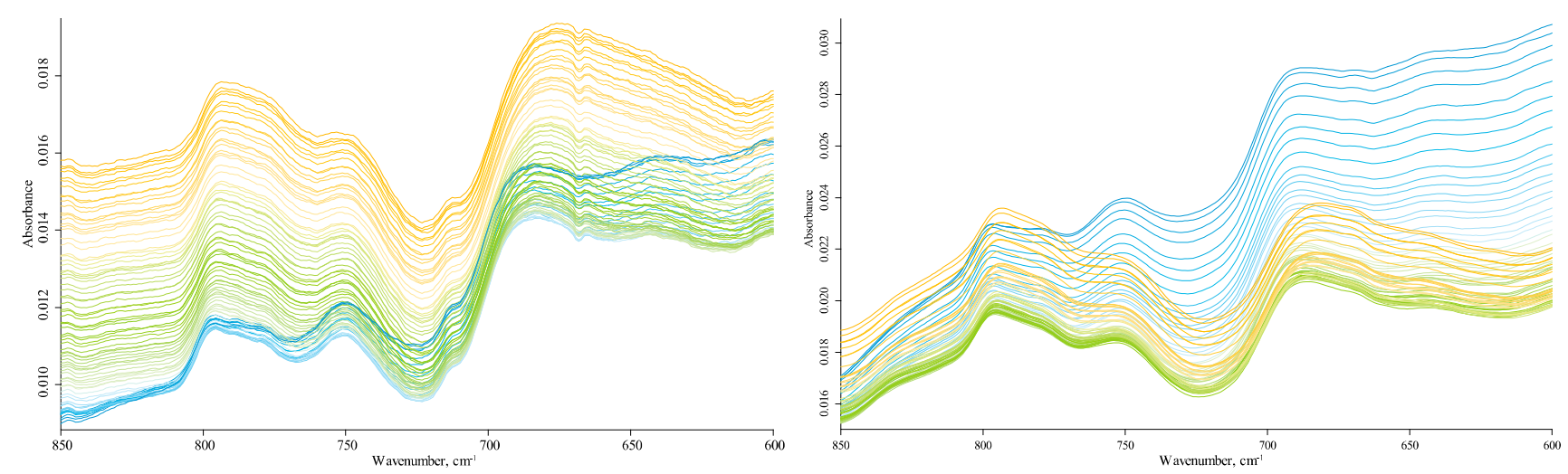

Figure 3. IR absorption spectra in the region $850-600 \mathrm{~cm}^{-1}$ after ATR correction of Sigma-Aldrich (left) and Powhumus (right) without centrifugation. Temperature increases from 25 to $215^{\circ} \mathrm{C}$ from blue to orange lines.

The band at $535 \mathrm{~cm}^{-1}$ experiences a redshift, probably indicating a second-order (overtone) band of the primary lattice vibration at $263 \mathrm{~cm}^{-1}$. The same can be assumed for the intense signature band at $697 \mathrm{~cm}^{-1}$ as it has a counterpart lattice vibration at $398-400 \mathrm{~cm}^{-1}$ [80]. Bands of $535 \mathrm{~cm}^{-1}$ and $460 \mathrm{~cm}^{-1}$ are red-shifted compared to kaolinite spectra, while the band of $455 \mathrm{~cm}^{-1}$, the principal band in kaolinite, is either insignificant or much lower in intensity in HS.

The bands at 775 and $750 \mathrm{~cm}^{-1}$ do not belong to quartz lattice frequencies, and they do not shift, which is clear from comparing with neighboring quartz bands. Likewise, the band at $715 \mathrm{~cm}^{-1}$ is not attributed to any lattice bands of quartz or silicate minerals, and its position does not change with temperature so that it can be the manifestation of OM, in-phase rock $\mathrm{CH}_{2}$ vibrations of $\mathrm{C}_{4+}$ alkanes [69], or polyaromatic entities [67].

A rather broad band at 700-500 $\mathrm{cm}^{-1}$ with main components at $640 \mathrm{~cm}^{-1}$ and $610 \mathrm{~cm}^{-1}$ is attributed to water librations [73]. Its intensities decrease with temperature (Figure 3), which contrasts with the behavior of other bands in this region. Both bands disappear at temperatures of $75-80{ }^{\circ} \mathrm{C}$. This behavior is in league with water bands at $1640 \mathrm{~cm}^{-1}$ and $3690 \mathrm{~cm}^{-1}$ and the hydrogen-bond ensemble (see Sections 3.4.3 and 3.4.5 below) attributed to loosely bound water. Water absorption decrease with temperature reveals a weak band at $670-665 \mathrm{~cm}^{-1}$, which does not shift with the temperature and may be 
attributed to $\mathrm{CO}_{2}$. A band at $425 \mathrm{~cm}^{-1}$ can be attributed to $\mathrm{C}-\mathrm{C}$ vibrations, but this is rather spurious due to its low intensity and only reliable appearance in the Sigma-Aldrich sample.

\subsubsection{Quartz-Overtone-Band Region (1270-800 $\mathrm{cm}^{-1}$ )}

All bands in this region experience a redshift with similar parameters (Figure 4) except for the carbonate band at $875 \mathrm{~cm}^{-1}$ (Figure 5). Following the literature [32], these are overtone lattice bands in $\alpha$-quartz shifting due to changing lattice parameters [90]. Broad bands at around $1030 \mathrm{~cm}^{-1}$ (Figure 6) and 1120-1070 $\mathrm{cm}^{-1}$ (Figure 7) can be considered the total $\mathrm{SiO}_{2}$ components as they are characteristic of both amorphous and crystalline species $[32,68,80,90,91]$. However, the band behavior at $1030 \mathrm{~cm}^{-1}$ is similar to that of $1010 \mathrm{~cm}^{-1}$.
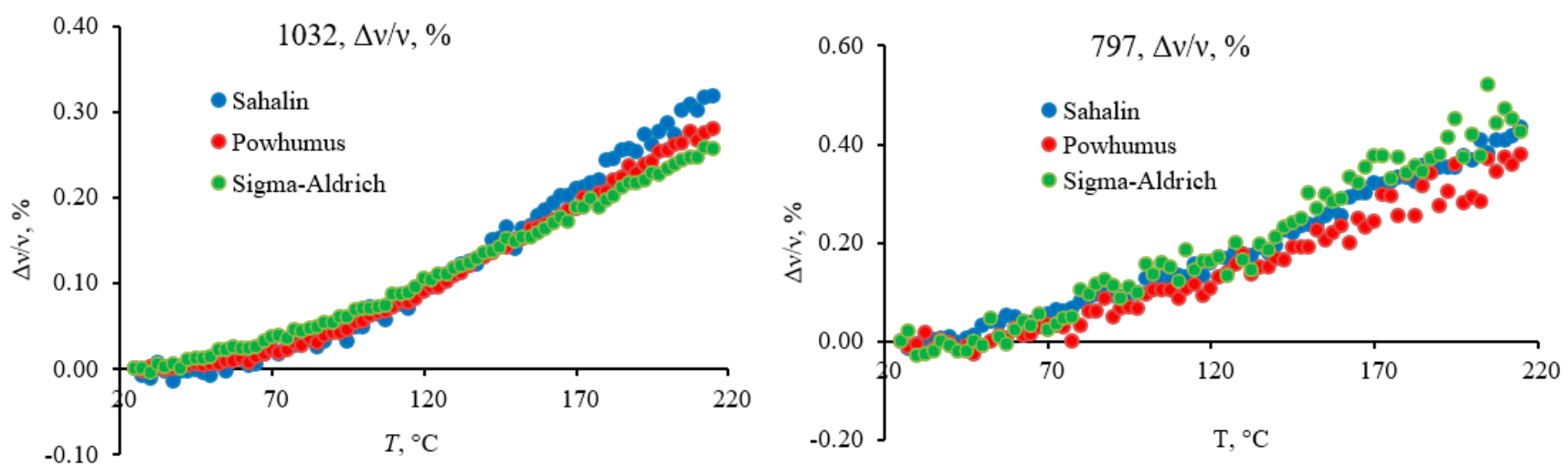

Figure 4. Redshifts of the smoothed bands at $1032 \mathrm{~cm}^{-1}$ and $797 \mathrm{~cm}^{-1}$ relative to $25^{\circ} \mathrm{C}$ temperature for HS samples.
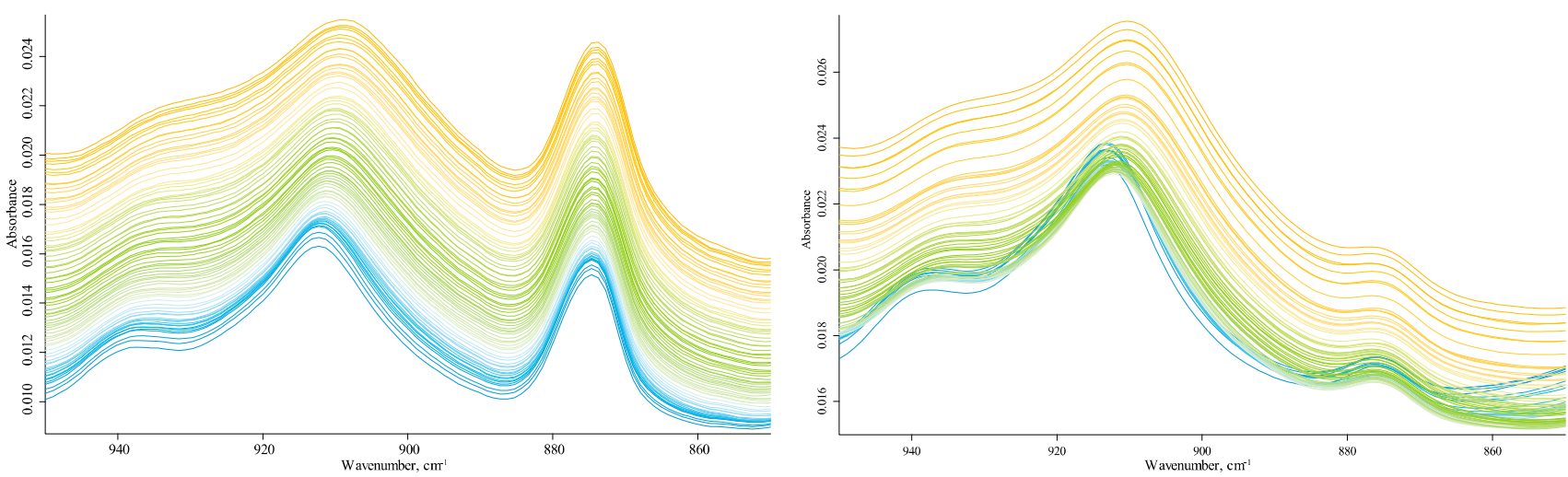

Figure 5. IR absorption spectra in the region $950-850 \mathrm{~cm}^{-1}$ after ATR correction of Sigma-Aldrich (left) and Powhumus (right) without centrifugation. Temperature increases from 25 to $215^{\circ} \mathrm{C}$ from blue to orange lines.

However, the band at $1120-1070 \mathrm{~cm}^{-1}$ is absent in kaolinite, so it may be partially attributed to HSOM (in-plane C-H bending of non-aromatic and cellulose species [92]). Still, if we follow the concept of temperature-independent non-quartz vibrations, no such components are found in this broad band. It can be deconvoluted into two components at $1110 \mathrm{~cm}^{-1}$ and $1070 \mathrm{~cm}^{-1}$ that experience similar and synchronous redshifts, so they must be attributed to quartz overtone components. This band is roughly the same as the dual structure of temperature experiments for quartz samples. The carbonate band at $875 \mathrm{~cm}^{-1}$ and its companion at $840 \mathrm{~cm}^{-1}$ is visible at low temperatures (Figure 4), less affected by water bands, and does not decrease at the end of the temperature cycle. 

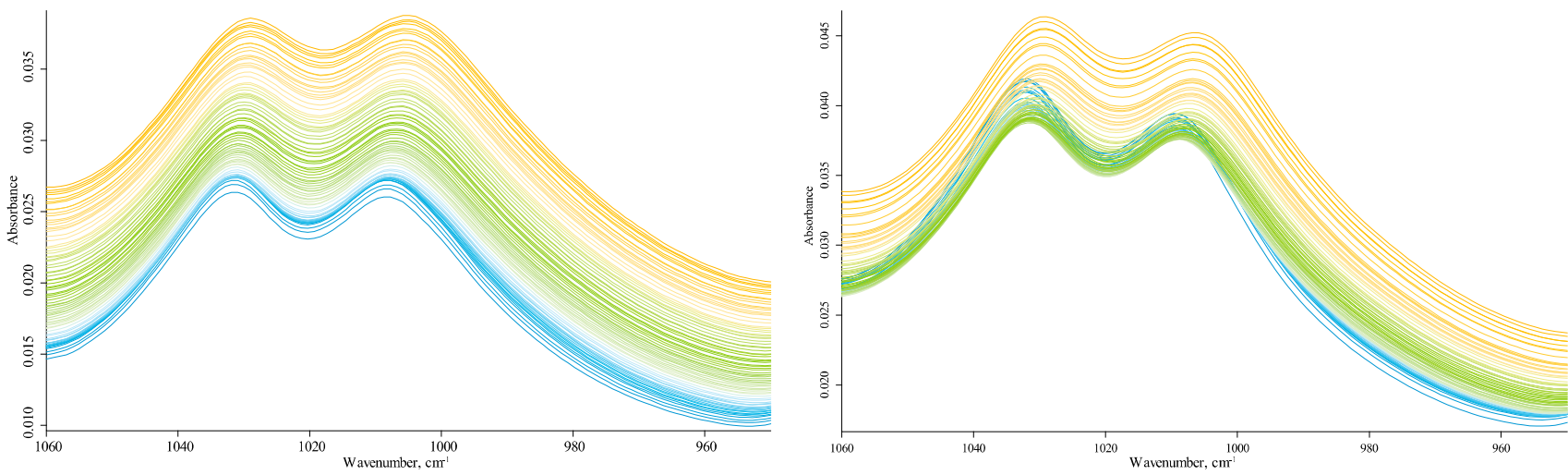

Figure 6. IR absorption spectra in the region 1060-950 $\mathrm{cm}^{-1}$ after ATR correction of Sigma-Aldrich (left) and Powhumus (right) without centrifugation. Temperature increases from 25 to $215^{\circ} \mathrm{C}$ from blue to orange lines.
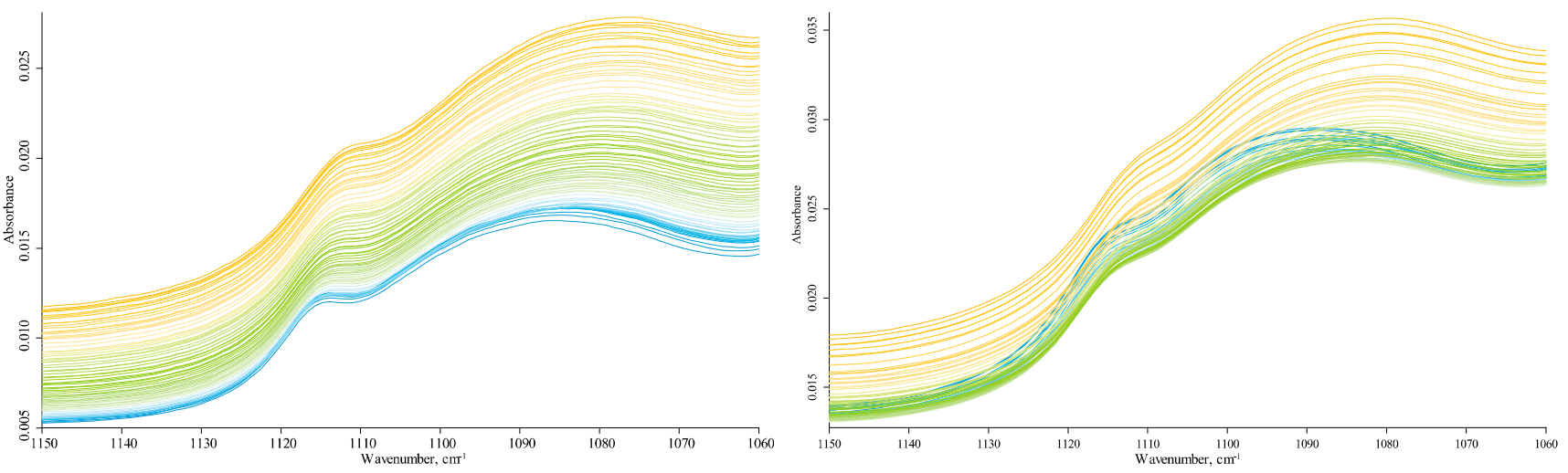

Figure 7. IR absorption spectra in the region 1150-1060 $\mathrm{cm}^{-1}$ after ATR correction of Sigma-Aldrich (left) and Powhumus (right) without centrifugation. Temperature increases from 25 to $215^{\circ} \mathrm{C}$ from blue to orange lines.

\subsubsection{HSOM Region (1780-1270 $\left.\mathrm{cm}^{-1}\right)$}

All bands except for $1380 \mathrm{~cm}^{-1}$ (Figure 8 ) and $1580 \mathrm{~cm}^{-1}$ (Figure 9) are temperatureindependent, which is evidence that they are not overtone counterparts of matrix vibrations of quartz and belong to isolated group vibrations. The pair of $1580 \mathrm{~cm}^{-1}$ and $1380 \mathrm{~cm}^{-1}$ (antisymmetric and symmetric carboxylate stretches, respectively) is dominated by combination vibrations $[93,94]$ and behaves as expected (such as hydrogen-bond ensembles), Figure 10. The antisymmetric band exhibits a blueshift, while the counterpart symmetric band shows a redshift. The antisymmetric band blueshift is significantly higher than the redshift in the symmetric vibration, which may be accounted for the effect on the highwavenumber edge of this band from decreasing water amount with temperature. The latter fact is confirmed by the change in the slope of the temperature change of $120^{\circ} \mathrm{C}$.

The absence of temperature-dependent vibrations around $1700 \mathrm{~cm}^{-1}$ at low temperatures shows that HS carboxylic groups are mainly carboxylate species. Such significant shifts in carboxylate bands show some similarity with $\mathrm{Si}-\mathrm{OH}$ bands in the hydrogenspeciation region (see below, Section 3.4.5). The series increasing bands at $1750 \mathrm{~cm}^{-1}$ and $1730-1720 \mathrm{~cm}^{-1}$ (carboxylic $\mathrm{C}=\mathrm{O}$ ) with the temperature (Figure 9) may be evidence of increasing amounts of the carboxylic acid species, which is confirmed by the correlated increase in the band at $1260 \mathrm{~cm}^{-1}$ characteristic to carboxylic $\mathrm{C}-\mathrm{OH}$. Additionally, other small increasing bands at $1700 \mathrm{~cm}^{-1}, 1695 \mathrm{~cm}^{-1}, 1685 \mathrm{~cm}^{-1}, 1650 \mathrm{~cm}^{-1}, 1640 \mathrm{~cm}^{-1}$, and $1620 \mathrm{~cm}^{-1}$, which are present for all HS samples, could be different carboxyl anions appearing at high temperatures as well. 

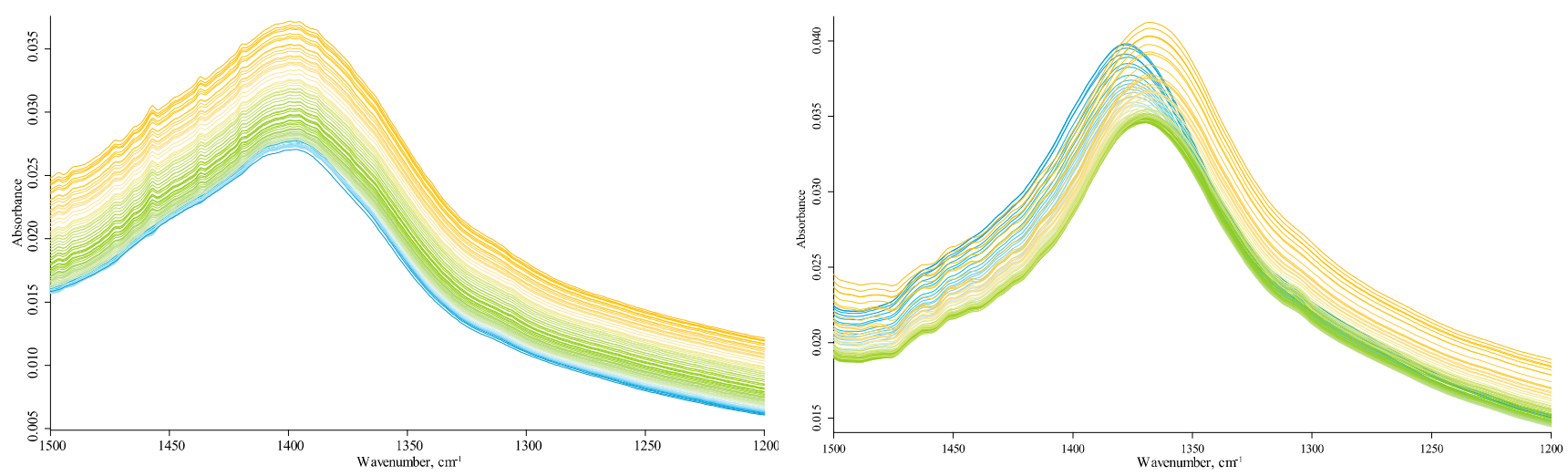

Figure 8. IR absorption spectra in the region 1500-1200 $\mathrm{cm}^{-1}$ after ATR correction of Sigma-Aldrich (left) and Powhumus (right) without centrifugation. Temperature increases from 25 to $215{ }^{\circ} \mathrm{C}$ from blue to orange lines.
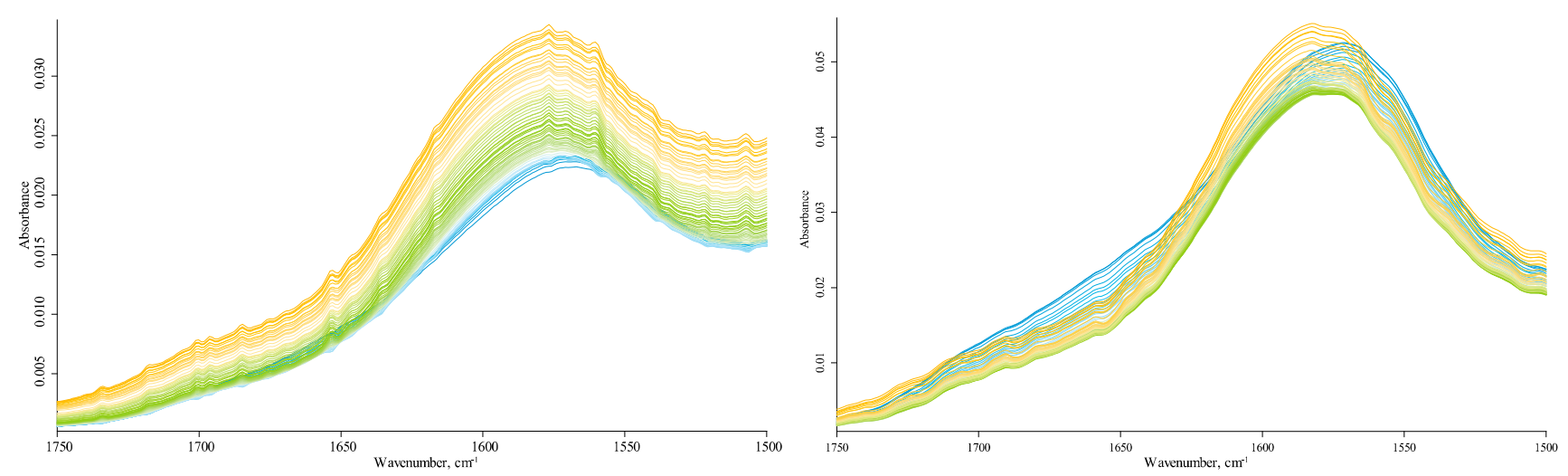

Figure 9. IR absorption spectra in the region $1750-1500 \mathrm{~cm}^{-1}$ after ATR correction of Sigma-Aldrich (left) and Powhumus (right) without centrifugation. Temperature increases from 25 to $215{ }^{\circ} \mathrm{C}$ from blue to orange lines.

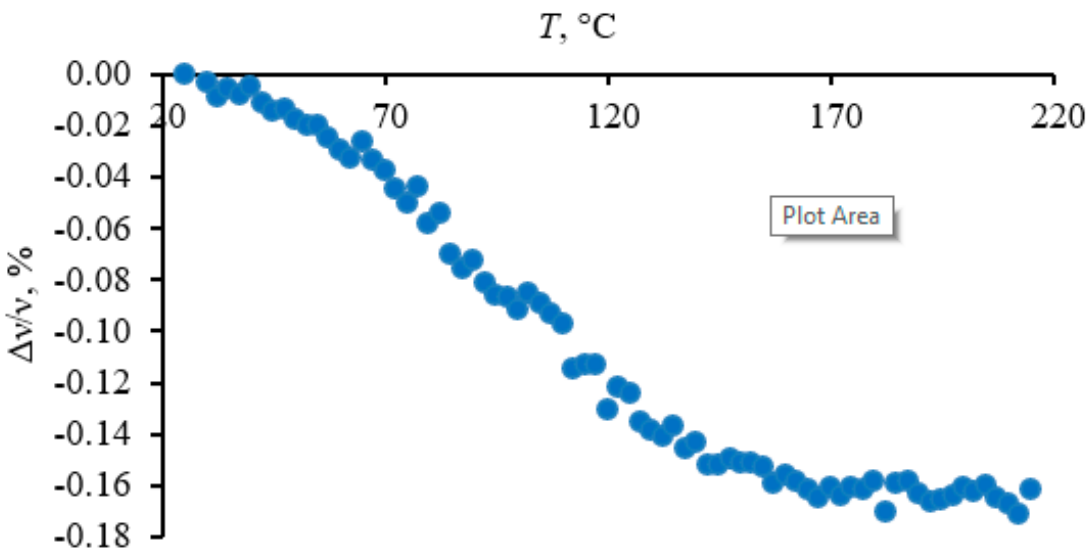

Figure 10. Blueshift of the smoothed band at $1573 \mathrm{~cm}^{-1}$ relative to $25{ }^{\circ} \mathrm{C}$ on temperature for the Sakhalin sample.

The water band position at $1640 \mathrm{~cm}^{-1}$ at the shoulder does not prevent the analysis of the principal band. The position of the center of the broad band of water around 1645-1640 $\mathrm{cm}^{-1}$ may be evidence of the loosely absorbed water [95]. The temperatures at which the band at $1640 \mathrm{~cm}^{-1}$ decreases are not synchronous with other changes in this area, whereas they are similar to the behavior of the bands in the water libration area 
(700-500 $\mathrm{cm}^{-1}$, Figure 3), hydrogen-bond ensemble, and Si-OH bands in the speciation region (see below).

\subsubsection{Quartz-Combination-Band and CH-Speciation Regions}

All bands are temperature-independent in the quartz-combination-band region $\left(2800-1780 \mathrm{~cm}^{-1}\right)$, Figure 11 . All four signature bands in the $\mathrm{CH}$-speciation region are stable as expected for first-order isolated vibrations [74]. The estimation ratio of methyleneto-methyl shows 2:1, provided the absorption coefficient is the same [96]. Alkene/aromatic $\mathrm{CH}_{2}$ bands at 3100-3030 appear clearly in the whole region, but the whole structure is more resolved at temperatures over $85^{\circ} \mathrm{C}$. The decrease of the hydrogen-bond ensemble can account for this behavior. The intensities of these bands start to disappear at temperatures over $150{ }^{\circ} \mathrm{C}$ due to the volatilization of aromatic components. Small blue and redshifts, respectively, are observed for asymmetric and symmetric $\mathrm{C}-\mathrm{H}$ stretching of aliphatic groups as expected (Table 2).
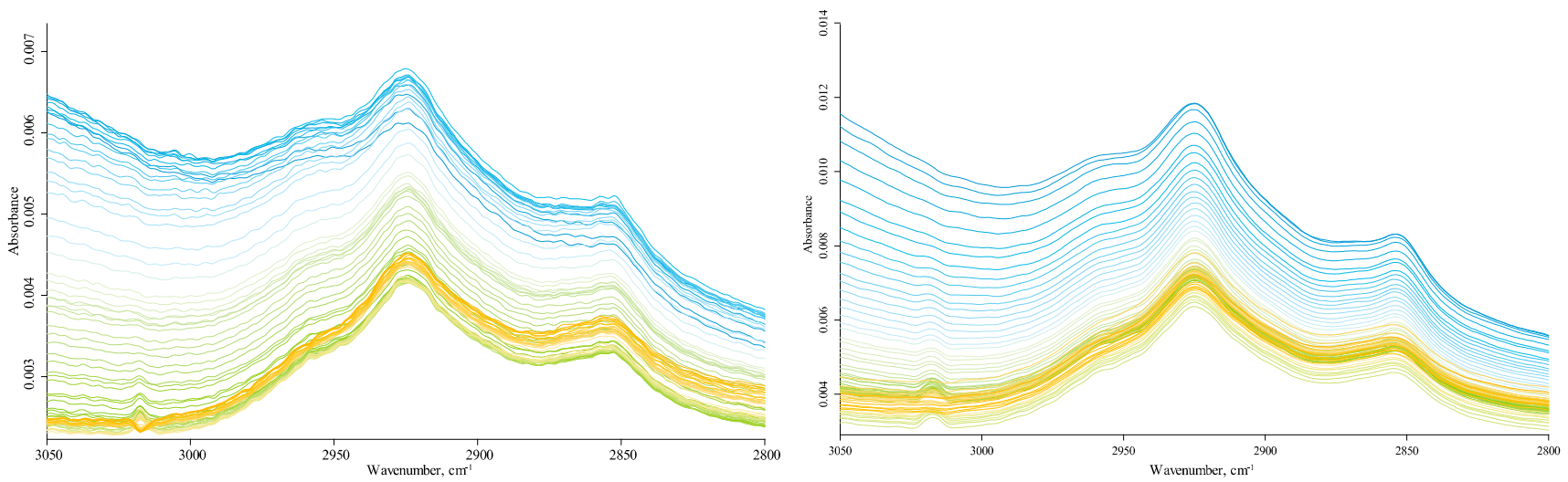

Figure 11. IR absorption spectra in the region 3050-2800 $\mathrm{cm}^{-1}$ after ATR correction of Sigma-Aldrich (left) and Powhumus (right) without centrifugation. Temperature increases from 25 to $215{ }^{\circ} \mathrm{C}$ from blue to orange lines.

\subsubsection{Hydrogen-Speciation Region $\left(4000-3100 \mathrm{~cm}^{-1}\right)$}

The band at $3692 \mathrm{~cm}^{-1}\left(3700-3680 \mathrm{~cm}^{-1}\right)$ shows a complex behavior with a general trend in the energy increase (Figure 12). This band experiences the most significant redshift by modulus (by $10 \mathrm{~cm}^{-1}$ for Powhumus and Sigma-Aldrich) among all the spectrum bands. The trend can be divided into three parts, a nearly stable band position (from 20 to $55^{\circ} \mathrm{C}$ ), a sharp twofold decrease in intensity with a redshift by ca. $2 \mathrm{~cm}^{-1}$ from 55 to $105^{\circ} \mathrm{C}$, and a monotonous redshift in the band maximum from 105 to $250{ }^{\circ} \mathrm{C}$, without a change in the band intensity. In addition, the shift in the band at $3692 \mathrm{~cm}^{-1}$ is accompanied by the appearance of red-shifting weak bands at $3710 \mathrm{~cm}^{-1}$ and $3715 \mathrm{~cm}^{-1}$ that can be attributed to unbonded $\mathrm{SiO}-\mathrm{H}$ stretch tilted vibrations in amorphous silica [82].

A band at $3620 \mathrm{~cm}^{-1}$ experiences a mirror-like blueshift behavior synchronous with the band at $3692 \mathrm{~cm}^{-1}$, although the whole shift is $5 \mathrm{~cm}^{-1}$. Both bands at $3700-3680 \mathrm{~cm}^{-1}$ and $3620 \mathrm{~cm}^{-1}$ are observed in kaolinite and attributed to amorphous and quartz $\mathrm{SiO}-\mathrm{H}$ bands [82]. Noteworthy is that the data on the bulk species of these bands (crystalline or amorphous) are contradictory [82], although all the authors claim these bands belong to hydrogen-bonded vibrations (Figure 13). According to the behavior of these bands, they are interconnected, and the initial part of the plots shows that they are attributed to loosely bound molecular water, which results in the initial slow shift followed by the more tightly bound water, which results in its loss from the amorphous silica matrix and more substantial shifts at higher temperatures. 

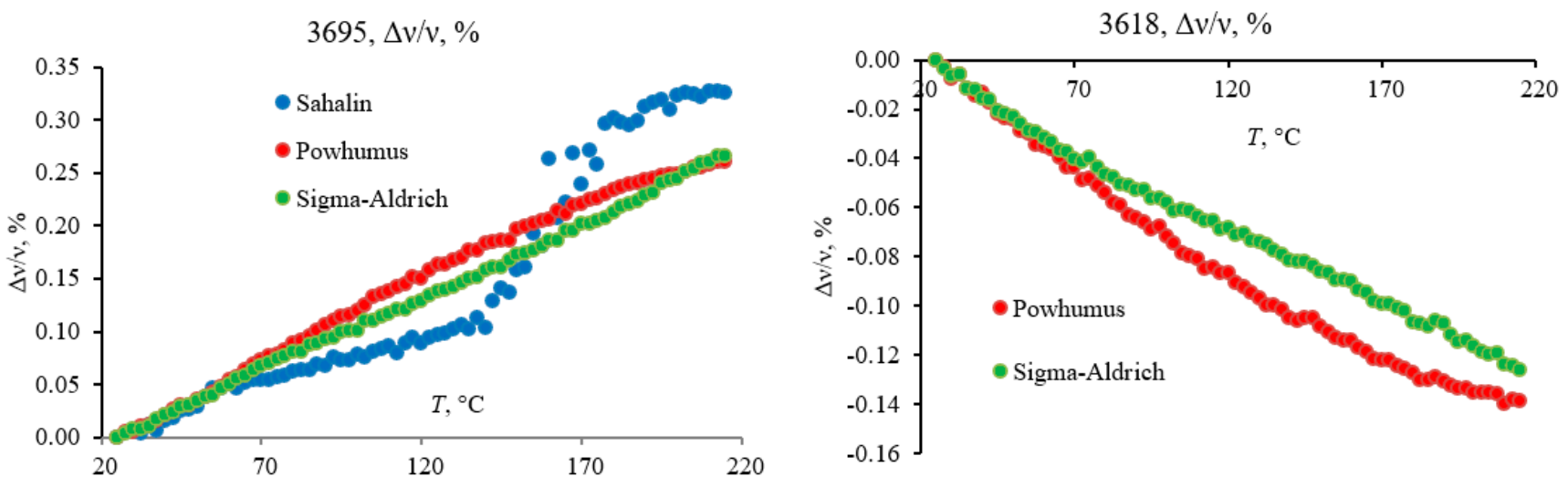

Figure 12. Redshift of the smoothed band at $3695 \mathrm{~cm}^{-1}$ and blueshift at $3618 \mathrm{~cm}^{-1}$ relative to $25^{\circ} \mathrm{C}$ temperature for HS samples.
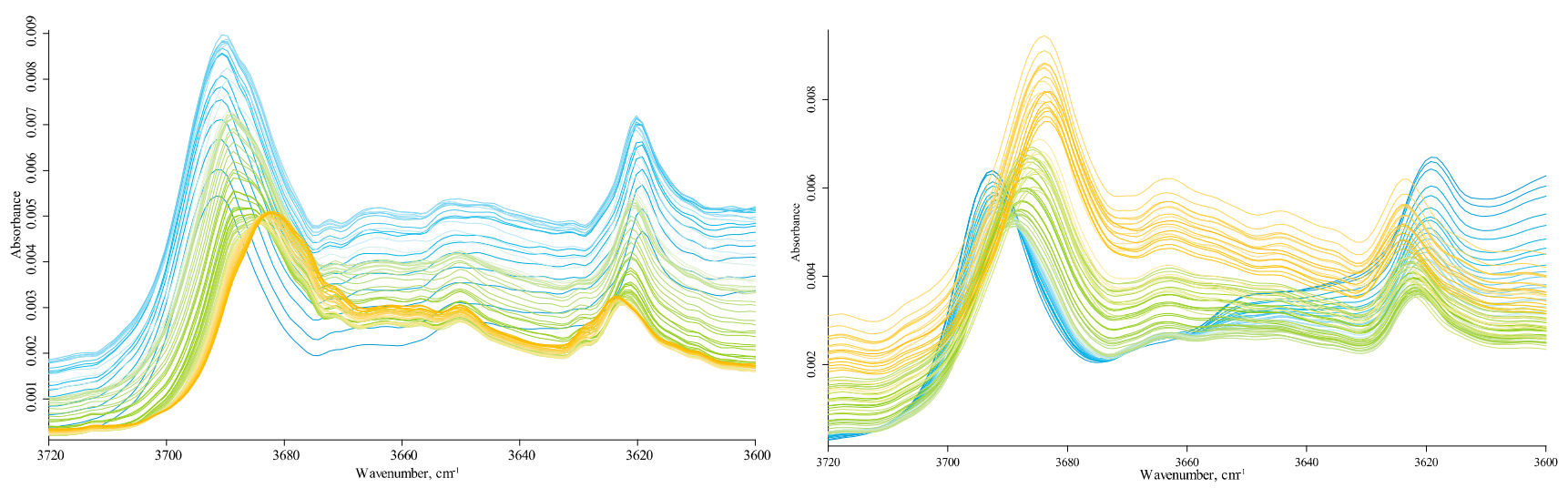

Figure 13. IR absorption spectra in the region $3720-3600 \mathrm{~cm}^{-1}$ after ATR correction of Sigma-Aldrich (left) and Powhumus (right) without centrifugation. Temperature increases from 25 to $215^{\circ} \mathrm{C}$ from blue to orange lines.

The band at $3695 \mathrm{~cm}^{-1}$ seems unusual as dehydration results in the redshift despite expected loss in coordination and a blueshift [97]. This feature may be accounted for a change in coordination rather than isolation due to hydration. Another reason for such a behavior can be the ionic character of the related species so that the dehydration results in a more organized character of these bonds.

Bands at $3655 \mathrm{~cm}^{-1}, 3645 \mathrm{~cm}^{-1}, 3665 \mathrm{~cm}^{-1}, 3635 \mathrm{~cm}^{-1}$, and $3610 \mathrm{~cm}^{-1}$ are assigned as $\mathrm{OH}$ of alcohol/phenolic species [74]; the latter three are equal in intensities, which slightly increase with temperature and do not shift. Therefore, they are not coincident with the bands attributed to pure kaolin samples. On the contrary, a change in the region of $3660-3640 \mathrm{~cm}^{-1}$ cannot be attributed to a simple shift. This behavior is different for all three samples due to the formation of isolated $\mathrm{OH}$ species from the neighboring species, resulting in a rather acute redshift by $5 \mathrm{~cm}^{-1}$.

Condensed-phase antisymmetric $\left(3400 \mathrm{~cm}^{-1}\right)$ and symmetric $\left(3290 \mathrm{~cm}^{-1}\right)$ hydrogenbond ensembles behave as predicted: the energy of antisymmetric vibrations increases and the energy of symmetric vibrations decreases [98] monotonously.

\subsection{Differences between HS Samples}

The samples have almost the same set of prominent bands, differing mainly in their intensity ratios. The behavior of all quartz and silica bands for all the samples is the same; all the signature bands of quartz and kaolinite are attributable; the difference is only the relative intensity or the shape (band or shoulder). No significant differences between the samples were found in the quartz-combination-band $\left(2800-1780 \mathrm{~cm}^{-1}\right)$ and $\mathrm{CH}$-speciation $\left(3100-2800 \mathrm{~cm}^{-1}\right)$ regions. 
The bands at $715 \mathrm{~cm}^{-1}$ and $425 \mathrm{~cm}^{-1}$ are reliable only in Sigma-Aldrich; the $\mathrm{CO}_{2}$ band at $667 \mathrm{~cm}^{-1}$ is much broader in Powhumus and is very weak in the Sakhalin sample. In the Sakhalin sample, the band with a maximum at $875 \mathrm{~cm}^{-1}$ is absent; in the rest of the samples, it differs in intensity much more strongly than the other bands. The bands at $875 \mathrm{~cm}^{-1}$ and $840 \mathrm{~cm}^{-1}$ in Sigma-Aldrich are more intense than in Powhumus and Sakhalin (barely identified in the latter sample).

All the primary and minor bands in the HSOM region are the same for all three samples, but the intensity ratio for carboxylate bands of Powhumus and Sakhalin is different from Sigma-Aldrich. This difference may result from different HA counterions, potassium for the former two, and sodium for Sigma-Aldrich. This ratio inversely correlates with the band at $875 \mathrm{~cm}^{-1}$. The symmetric carboxylate stretch band for Sigma-Aldrich does not experience a significant shift with temperature.

The bands at $3665 \mathrm{~cm}^{-1}, 3655 \mathrm{~cm}^{-1}, 3645 \mathrm{~cm}^{-1}, 3635 \mathrm{~cm}^{-1}$, and $3610 \mathrm{~cm}^{-1}$ are the same for all the samples; however, the behavior of the broad band at $3700-3680 \mathrm{~cm}^{-1}$ is somewhat different. Comparing the three HS samples shows that this band is a poorly resolved or unresolved band with maxima at $3685 \mathrm{~cm}^{-1}$ and $3695 \mathrm{~cm}^{-1}$. It is not apparent in Sigma-Aldrich and Powhumus but is seen in the Sakhalin sample and confirmed (though with a high overall error) by centrifuged samples.

Thus, the overall anomalously large redshift is apparent. A decrease in the band at $3695 \mathrm{~cm}^{-1}$ and an increase in the band at $3685 \mathrm{~cm}^{-1}$, along with an intensity decrease in the hydrogen-bond ensemble band edge, visually shifts this band to lower wavenumbers.

\subsection{Uncentrifuged and Centrifuged Samples}

The decrease in intensities of most quartz lattice bend vibrations, which are removed upon centrifugation (see Figures 1 and 14), is shown, while the bands corresponding to the generic $\mathrm{SiO}_{2}$ vibrations or amorphous silica $\left(1030 \mathrm{~cm}^{-1}, 915 \mathrm{~cm}^{-1}, 797 \mathrm{~cm}^{-1}, 697 \mathrm{~cm}^{-1}\right.$, $535 \mathrm{~cm}^{-1}$, and $465 \mathrm{~cm}^{-1}$ ) remain. This decrease is confirmed by changes in intensities of other bands attributed to crystalline/amorphous $\mathrm{SiO}_{2}$ (see below, Section 4.1.3). As well, in the quartz-overtone-band region, most bands attributed to crystalline quartz disappear after centrifugation, while $\mathrm{SiO}_{2}$ bands characteristic of amorphous species remain. The intensity of bands that may be attributed to polyaromatic compounds significantly decreases after centrifugation (reliably confirmed for Powhumus HS only).

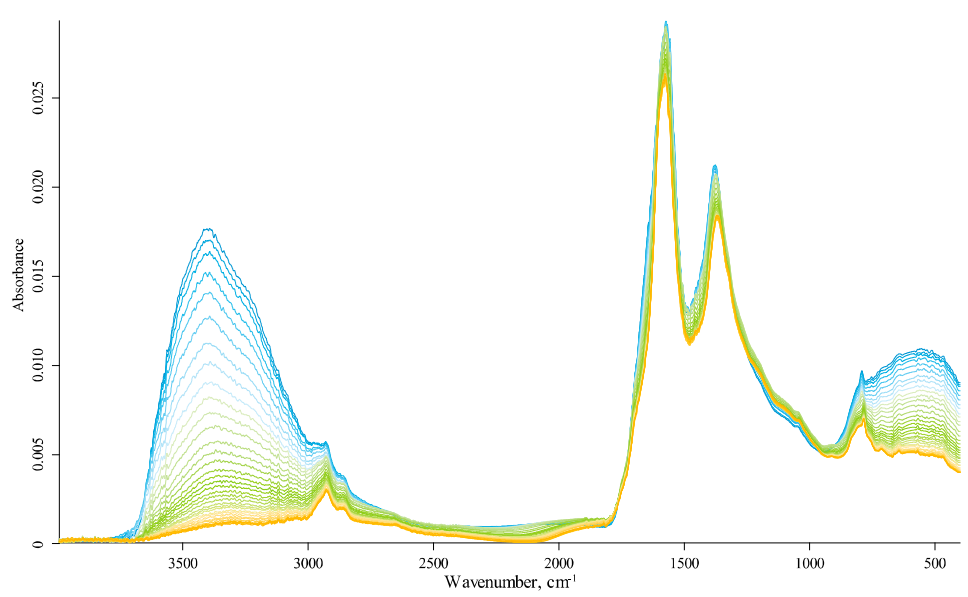

Figure 14. IR absorption spectra in the region $4000-400 \mathrm{~cm}^{-1}$ after ATR correction of Powhumus sample after centrifugation. Temperature increases from 25 to $215^{\circ} \mathrm{C}$ from blue to orange lines.

Centrifugation does not change the overall picture but reveals the band complex structure at $1590 \mathrm{~cm}^{-1}$. Thus, probably partly, this band contains hydrogen-bonded amorphous $\mathrm{SiOH} \ldots \mathrm{H}_{2} \mathrm{O}$ HO-H stretch. The broad carboxylic $\mathrm{O}-\mathrm{H}$ stretch is present in both uncentrifuged and centrifuged samples, which may be proof of its nature. The band is weak, but its intensity increases along with other carboxylic bands in increasing 
temperature. A broad and weak band at $2430 \mathrm{~cm}^{-1}$ is also present in both samples, but its assignment to amine vibrations is not proven due to its low intensity.

No significant differences except for the spectra of centrifuged samples at high temperature reveal fine structures of bands $\left(3020-3100 \mathrm{~cm}^{-1}\right)$ that may be attributed to aromatic stretch and confirm other bands attributed to aromatic species. Hydrogen-speciation region (4000-3100 $\mathrm{cm}^{-1}$ ): all SiO-H bands significantly decrease in intensity; the bands at $3665 \mathrm{~cm}^{-1}, 3655 \mathrm{~cm}^{-1}, 3645 \mathrm{~cm}^{-1}$, and $3635 \mathrm{~cm}^{-1}$ remain approximately the same.

As a whole, the comparison of the temperature behavior of centrifuged and uncentrifuged samples shows that the effect of hydrogen-bond ensemble affects the region up to $3700 \mathrm{~cm}^{-1}$ more or less monotonically (a constant decrease with the temperature, while the edge of this continuum decreases significantly, which may affect the shape and behavior of the bands at $3700 \mathrm{~cm}^{-1}$.

\section{Discussion}

\subsection{Components}

\subsubsection{HSOM}

Thus, the comparison of spectra of different samples and in the studied temperature range shows that aliphatic compounds/groups are represented by all signature bands. They are methylene and methyl stretch at $3000-2800 \mathrm{~cm}^{-1}$ (Figure 11), $\mathrm{CH}_{2}$ scissoring at $1460 \mathrm{~cm}^{-1}$ (Figure 8), probably $\mathrm{CH}_{2}$ wagging/twisting at $1310 \mathrm{~cm}^{-1}$ (Figure 8), and in-plane bend vibrations at $715 \mathrm{~cm}^{-1}$ (Figure 3). All bands attributed to aliphatic compounds/groups are temperature-independent.

The presence of aromatic compounds is possible due to the existence of almost all characteristic bands: (1) $-\mathrm{C}=\mathrm{C}-$ stretch [99] at $1540-1560 \mathrm{~cm}^{-1}$ (Figure 9); (2) substituted / polyaromatic bands at 1660-1700 $\mathrm{cm}^{-1}$ (Figure 9), and (3) the band of $=\mathrm{C}-\mathrm{H}$ stretch at $3020 \mathrm{~cm}^{-1}$ (Figure 11). In addition, aromatic in-plane $=\mathrm{C}-\mathrm{H}$ bend in 1090-1060 $\mathrm{cm}^{-1}$ may contribute to the broad complex band at $1110-1070 \mathrm{~cm}^{-1}$ (Figure 7). All bands attributed to aromatic compounds are temperature-independent. An exciting feature of aromatic bands is their appearance after eliminating the loosely bound molecular water (3400-3000 $\mathrm{cm}^{-1}, 1660-1630 \mathrm{~cm}^{-1}$ : Figure 9, and 650-600 $\mathrm{cm}^{-1}$ : Figure 3.) followed by a synchronous decrease (though relatively small) in the band intensities upon temperatures of $150{ }^{\circ} \mathrm{C}$. As aromatic compounds are stable at the used range of temperatures, such behavior may evidence the volatilization of aromatic compounds, i.e., low-molecular entities containing aromatic compounds. Such behavior was shown for all three HS samples for $3400-3000 \mathrm{~cm}^{-1}$, while changes at $1660-1630 \mathrm{~cm}^{-1}$ were only reliably found for Powhumus.

Concerning functional groups, as expected, HS is dominated by the carboxylate bands, which form an antisymmetric/symmetric pair. According to the existing studies [100], the maxima of HSOM carboxylate bands correspond to $\alpha$-substituted aliphatic carboxylic acids and possibly halogen-substituted and aromatic carboxylic acids. The temperature behavior shows the appearance and synchronous growth of a series of nearly located bands at $1740-1300 \mathrm{~cm}^{-1}$ (Figures 8 and 9) that can be considered isolated unbonded carboxyl species, though they also manifest aliphatic and aromatic group vibrations. No other functional groups can be reliably attributed.

The absence of the carboxylic acid band at $1700 \mathrm{~cm}^{-1}$ and two broad dominating carboxylate bands shows that the latter is the major carboxylic species in these samples. The presence of carboxylic $\mathrm{O}-\mathrm{H}$ fully confirms the low-energy-range bands. The aliphatic-toaromatic ratio in the $\mathrm{CH}$-speciation region $\left(3100-2800 \mathrm{~cm}^{-1}\right.$ ) can be estimated in principle, but this would result in relatively high uncertainty due to overlapping bands of aromatic bands with other constituents. At least four kinds of $\mathrm{Si}-\mathrm{OH}$ groups and three types of water can be attributed in HS, summed up below (Section 4.1.3). 


\subsubsection{Water}

Three types of water can be attributed to HS. First is loosely bound molecular water that dehydrates below $200{ }^{\circ} \mathrm{C}$ and is a minor component in the studied samples. The bands are $3400 \mathrm{~cm}^{-1}$ and $3290 \mathrm{~cm}^{-1}$ (Figure 11), the bend at $1640 \mathrm{~cm}^{-1}$ (Figure 9) [101], and, though with some doubts, librations at $640 \mathrm{~cm}^{-1}$. The bands decrease synchronously, insignificantly affect other bands, and do not depend on sample centrifugation.

Another type of water is tightly bound molecular water that dehydrates above $350{ }^{\circ} \mathrm{C}$. This kind of water is bonded to surface-Si-OH groups. The $3740 \mathrm{~cm}^{-1}$ and $3660 \mathrm{~cm}^{-1}$ bands due to surface $\mathrm{Si}-\mathrm{OH}$ appeared upon the dehydration of this type of water. These bands are absent in centrifugated samples. Finally, there is water tightly bound to HSOM, according to the behavior of weak bands at $3660-3640 \mathrm{~cm}^{-1}$; this type of water is not bound to $\mathrm{OH}$ groups and instead provides the coordination of the carboxylic groups. The same type of water is also expected for temperature changes in carboxylate bands and causes the appearance of $\mathrm{C}=\mathrm{O}$ and $\mathrm{C}-\mathrm{OH}$ bands. Significant shifts in carboxylate bands could result from two simultaneously acting factors: an intrinsic change in vibrations and the blueshift due to the decrease in the hydrogen bond coordination effect of carboxylate anion with water molecules [28].

\subsubsection{Quartz Bulk}

The behavior of $\mathrm{SiO}_{2}$ in $\mathrm{HS}$ is as expected [32], and all the bands attributed to quartz fall into three categories. First are fundamental frequencies of $\alpha$-quartz, which are stable, temperature-independent, and coincident with natural $\alpha$-quartz samples at $700-400 \mathrm{~cm}^{-1}$. Second, lattice O-Si-O stretch vibrations at $797 \mathrm{~cm}^{-1}$ exhibit a small temperature redshift due to changes in the lattice parameters. Finally, most of the intense combination and overtone bands of bulk quartz in the region $1100-600 \mathrm{~cm}^{-1}$ experience a significant redshift due to the changes in the lattice parameters and the theory of the second-order bands ${ }^{\prime}$ temperature behavior [90]. Along with a decrease in the bond length, the energy of the associated phonon increases. Frequency increases as pressure increases or temperature decreases, and therefore, the wavelength of the band must decrease. Tetrahedral Si-O bond lengths and bond angles are relatively incompressible compared to the spacings between the oxygen and metal ions and inter-tetrahedral oxygen atoms, so there is slight variation in the wavelength corresponding to the $10 \mathrm{~mm}$ stretching and $20 \mathrm{~mm}$ bending features with temperature (e.g., [32]). In contrast, the volumes of the divalent cation sites are more compressible. Therefore, one would expect to see a more significant change in the wavelengths of bands associated with the cation sites. Under the conditions of ATR experiments, most bands are fundamental or overtones, while the intensity of combination bands at 2000-1800 $\mathrm{cm}^{-1}$ seen in DRIFT [102] and PAS-FTIR [72] are not seen (Figure 1).

The reliably stable fundamental frequencies of quartz matrix and characteristic redshifts of the combination and overtone bands make it possible to distinguish signature bands of HS organic matter even at relatively low temperatures at such a heating experiment, meaning no severe sample degradation.

\subsubsection{Quartz Surface (Si-OH) Groups}

At least four kinds of $\mathrm{Si}-\mathrm{OH}$ groups can be attributed: (1) $\mathrm{Si}-\mathrm{OH}$ groups are located at the silica surface, and open structural defects in quartz are bound to water [97]. The band is at $3620 \mathrm{~cm}^{-1}$ at $20^{\circ} \mathrm{C}$ and shifts to $3625 \mathrm{~cm}^{-1}$ with increasing temperature (Figure 10). Dehydration is the easiest among the three hydroxyl groups. (2) $\mathrm{Si}-\mathrm{OH}$ groups close together to be hydrogen-bonded to each other. This group probably represents the absorption band at $3660 \mathrm{~cm}^{-1}$, which does not shift significantly with temperature. The organic $\mathrm{OH}$ groups can also cause this band. (3) Non-water coordinated $\mathrm{Si}-\mathrm{OH}$ groups (overlapped band at $3695-3685 \mathrm{~cm}^{-1}$ with an anomalous behavior). The coordination of water most probably causes this band, and the changes with temperature result from the change in coordination. (4) Isolated surface $\mathrm{Si}-\mathrm{OH}$ groups free of hydrogen bonding (the absorption 
band at $\left.3715 \mathrm{~cm}^{-1}\right)$. At $25^{\circ} \mathrm{C}$ and on the increase to $215^{\circ} \mathrm{C}$ and dehydration of loosely attached water molecules, the band grows gradually with a slight redshift to $3712 \mathrm{~cm}^{-1}$.

\subsection{Comparison of HS Samples}

The three samples are remarkably similar, and the majority of conclusions and assumptions are made by all the three samples and their comparison as a group with either quartz or kaolinite samples. Sigma-Aldrich, Powhumus, and Sakhalin samples have almost identical bands, differing mainly in intensity ratios. Mostly identical are quartz lattice fundamental vibrations and confirmed or probable overtones and bands corresponding to total $\mathrm{SiO}_{2}$ or amorphous species. In the HSOM region, all the samples show the same degree of ionization of HSOM acidic groups (carboxylate bands) and minor series of bands corresponding to carboxylic or aromatic bands and their temperature behavior. Additionally, the spectra show many similarities in (i) the types of bound water and the corresponding temperature behavior; (ii) methyl/methylene ratio and alkyl/aryl $\mathrm{CH}_{2}$ groups; and (iii) the behavior of the complex hydrogen-bonded bands at $3695-3685 \mathrm{~cm}^{-1}$ and $3620 \mathrm{~cm}^{-1}$ and series of minor bands corresponding to $\mathrm{OH}$-groups in the hydrogen-speciation region. With the blueshift and the intensity decrease in the band at $3620 \mathrm{~cm}^{-1}$ (Section 3.5), we concluded that a single mechanism could cause this area's behavior. In our opinion, a possible mechanism can be a change in the character of bonding groups upon heating, when they do not shift to unbound groups with a well-defined, strong blueshift but change from water-bonded to HSOM-bonded or neighboring-group bonded.

Still, these three HS samples have different features. The Sigma-Aldrich sample is different from two other HS samples by positions and the ratio of carboxylate anion bands at $1580 \mathrm{~cm}^{-1}$ and $1380 \mathrm{~cm}^{-1}$, a more pronounced band at $2650 \mathrm{~cm}^{-1}$, a stronger carbonate band at $875 \mathrm{~cm}^{-1}$, and fewer bands in the region below $450 \mathrm{~cm}^{-1}$. The intensity difference at $875 \mathrm{~cm}^{-1}$ and $840 \mathrm{~cm}^{-1}$ in Sigma-Aldrich compared to Powhumus and Sakhalin may be due to the counterion $\left(\mathrm{Na}^{+}\right.$and $\mathrm{K}^{+}$, respectively).

The Sakhalin sample is different from two other HS samples by (i) the maximum number of bands in all the regions, (ii) a different ratio of bands at $3690-3680 \mathrm{~cm}^{-1}$ (surface $\mathrm{SiO}-\mathrm{H}$ groups), (iii) almost insignificant band at $875 \mathrm{~cm}^{-1}$, (iv) a different ratio and resolved character of the complex band at 3695-3685 $\mathrm{cm}^{-1}$, and (v) the resolved character of the carboxylate band at $1580 \mathrm{~cm}^{-1}$. Powhumus sample shows some similarities with either Sigma-Aldrich or Sakhalin samples. In the quartz and hydrogen-speciation regions, this sample is similar to Sigma-Aldrich, while in the HSOM region, to the Sakhalin sample.

\subsection{Summary}

Thus, the features of this approach can be summed up as follows. First, it provides a more detailed HS (and on its basis, probably soils) analysis without total HS decomposition or HSOM destruction. The temperature experiment agrees with the existing literature on quartz species $[32,90,91,97,103-105]$ and provides the differentiation of crystalline quartz bands, amorphous silica, and HSOM/surface groups. As a bonus, some similarities in the behavior of bands attributed to quartz species may suggest attributing them to overtone or fundamental frequencies of quartz. Second, the temperature experiment combined with centrifugation may help differentiate crystalline/amorphous matrix species and HS species connected to them. Additionally, the used time-resolved heating mode similar to TGA differentiates water elimination, volatilization of HS, and coordination changes, though for the remaining solid samples.

The disadvantages of the proposed can be summed up as follows. First of all, there are possible deficits in the approach that other studies can overcome. There are many relatively spurious band assignments with double and triple choices of HSOM, matrix, and inorganic surface groups, and all these assignments may be doubted (except quartz and major bands) and thus result in incorrect statements regarding the sample composition. For instance, aluminosilicate and silicate species cannot be reliably distinguished due to spurious data. In this study, we double-checked them using both the general spectrum interpretation 
and heating behavior and bulk composition of corresponding elements ( $\mathrm{Si}, \mathrm{Al}$ ). In our opinion, in all the cases, other methods such as XRD, NMR, AES, or chemical speciation (titration, ion exchange) should be used to correct the band attribution. The models other than quartz are needed to account separately for silicate surface groups, purified HSOM, and their potential interaction. No objective evidence of the chemical interaction of HSOM and matrix is found in the present state. As well, non-HSOM acidic surface groups are not revealed, although they may be present. Finally, almost all aryl groups are due to highly molecular HS or polyaromatics, or some aromatics are volatilized (along with water vaporization or afterward), resulting in relatively ambiguous data.

Apart from this, some more 'technical' drawbacks are due to the limited number of sample origins used in this study. Thus, a more detailed study is needed to distinguish quartz and other silicate minerals; the most challenging band at $875 \mathrm{~cm}^{-1}$ reveals too many candidates, and more samples are needed to conclude that this is undoubtedly the carbonate band. Furthermore, more evidence is needed in the hydrogen-speciation region and probably in NIR, as band assignment is now ambiguous. Additionally, relative to HS samples, the relevance of potassium and sodium effects on FTIR spectra is left unanswered, as well as other elements, including $\mathrm{Ca}, \mathrm{Fe}$, or Al. This could be the subject of the following study. Finally, the approach has another 'technical' drawback associated with the relative duration of measurements. However, it is comparable to the duration of thermogravimetric measurements and, in principle, can be further reduced by a factor of 2-4 due to a decrease in the number of scans and an increase in the heating rate. However, optimization of measurement conditions is a challenge for future research.

Additionally, low temperatures could be used to prove that the existing temperature behavior is not connected to water, while higher temperatures compared to the used range can be applied to account for irreversible changes in HSOM. These effects and other uncertainties in spectra would require more statistically wise studies with due account to the reproducibility of the changes upon temperature.

Apart from the concept of HSOM analysis by the proposed approach, the quartz lattice region (800-260 $\mathrm{cm}^{-1}$ ) can be used as a basis for estimating the amounts of crystalline forms of $\mathrm{SiO}_{2}$ and its ratio with amorphous Si-containing forms. The drawback is that all the bands are temperature-independent, so matrix vibrations are hard to distinguish from organic matter and other components. In the quartz-overtone-band region $\left(1270-800 \mathrm{~cm}^{-1}\right)$, the comparison of fundamental and overtone regions may be used to attribute the bands in the quartz spectrum more finely and compare the crystalline and amorphous species. The bands in this region that do not experience a redshift may be assigned to HSOM. The band at $1120-1070 \mathrm{~cm}^{-1}$ is most problematic as its structure is not revealed fully, either from temperature-based or centrifugation experiments. In HS, it is the least informative region; the only organic constituent may be ambiguous; the characteristic bands of structured quartz $2015 \mathrm{~cm}^{-1}, 1970 \mathrm{~cm}^{-1}$, and $1880 \mathrm{~cm}^{-1}[102,105,106]$ are not seen, which correlate well with data on the low sensitivity of ATR to quartz overtones [72].

\section{Conclusions}

Thus, temperature-monitored IR spectroscopy of humic substances provides a more detailed analysis without sample decomposition or HSOM destruction due to different temperature behavior of the maxima and intensities of bands of different components. Therefore, it may be considered a basis for a procedure capable of differentiation of crystalline quartz and amorphous inorganic bands and organic and functional groups of HS systems. Still, some studies are required to expand and strengthen the approach, which should involve the more certain assignment of bands, first of all, complex bands in $1700-1100 \mathrm{~cm}^{-1}$ region, and the use of independent physical and chemical methods along with temperature-based IR measurements.

Still, even in the present state, band-maximum temperature dependence can be considered more stable to changes in experimental conditions than band maxima at a single temperature and serve as a new quantitative parameter characterizing HS using IR spec- 
troscopy. Furthermore, as the main findings of this paper show independence on the HS origin, they can be used in studies involving other types of HS, especially for soils and polluted environments. Additionally, this approach can be used for chemical weathering in soils. The outlooks of this approach may also include studying the changes in HS composition and structure in processed samples used in biotechnology [2,14,15], medicine, and eco-chemistry [4]. Finally, correlation spectroscopy seems expedient for temperature variation to account more correctly for synchronous effects.

Supplementary Materials: The following are available online at https:/ / www.mdpi.com/article/10 .3390/agronomy11091822/s1, Figure S1: A single-channel spectrum of Powhumus humate sample. Figure S2: FTIR spectrum of Powhumus after the registration. Figure S3: Spectra of the Powhumus sample after ATR correction using various refractive indices. Figure S4: Spectra of the Powhumus sample after ATR correction using various refractive indices. Figure S5: IR Absorption spectra in the region $3740-3560 \mathrm{~cm}^{-1}$ after ATR correction. Figure S6: IR Absorption spectra in the region $1900-1200 \mathrm{~cm}^{-1}$ after ATR. Figure S7: IR Absorption spectra in the region $1200-820 \mathrm{~cm}^{-1}$ after ATR correction. Figure S8: IR Absorption spectra in the region $820-400 \mathrm{~cm}^{-1}$ after ATR correction. Figure S9: IR Absorption spectra in the region $4000-400 \mathrm{~cm}^{-1}$ after ATR correction of the Powhumus sample before and after heating and cooling. Figure S10: IR absorption spectra in the region $4000-400 \mathrm{~cm}^{-1}$ after ATR correction. Figure S11: IR absorption spectra in the region $4000-400 \mathrm{~cm}^{-1}$ after ATR correction of the Sakhalin sample before heating after heating and cooling.

Author Contributions: Conceptualization, D.S.V. and O.B.R.; methodology, D.S.V. and O.B.R.; formal analysis, M.A.P., O.B.R., and D.S.V.; investigation, D.S.V. and O.B.R.; resources, D.S.V.; data curation, D.S.V.; writing—original draft preparation, M.A.P. and D.S.V.; writing—review and editing, M.A.P., D.S.V., and O.B.R.; visualization, D.S.V.; supervision, M.A.P.; project administration, M.A.P.; funding acquisition, M.A.P. All authors have read and agreed to the published version of the manuscript.

Funding: This work was supported by The Russian Science Foundation, project number 19-13-00117.

Institutional Review Board Statement: Not applicable.

Informed Consent Statement: Not applicable.

Data Availability Statement: Not applicable.

Acknowledgments: This research was performed according to the Development program of the Interdisciplinary Scientific and Educational School of Lomonosov Moscow State University, 'The future of the planet and global environmental change'.

Conflicts of Interest: The authors declare no conflict of interest.

\section{References}

1. Malcolm, R.L. The uniqueness of humic substances in each of soil, stream and marine environments. Anal. Chim. Acta 1990, 232, 19-30. [CrossRef]

2. Kulikova, N.A.; Perminova, I.V. Interactions between Humic Substances and Microorganisms and Their Implications for Nature-like Bioremediation Technologies. Molecules 2021, 26, 2706. [CrossRef]

3. Stevenson, F.J. Humus Chemistry: Genesis, Composition, Reactions; Wiley: Hoboken, NJ, USA, 1994.

4. Perminova, I.V.; Garcia-Mina, J.-M.; Podgorski, D.C.; Cervantes, F.J.; Efremenko, E.N.; Domingo, J.L. Humic substances and living systems: Impact on environmental and human health. Environ. Res. 2021, 194, 110726. [CrossRef]

5. Winkler, J.; Ghosh, S. Therapeutic Potential of Fulvic Acid in Chronic Inflammatory Diseases and Diabetes. J. Diabetes Res. 2018, 2018, 5391014. [CrossRef]

6. Peña-Méndez, E.M.; Havel, J.; Patočka, J. Humic substances-compounds of still unknown structure: Applications in agriculture, industry, environment, and biomedicine. J. Appl. Biomed. 2005, 3, 13-24. [CrossRef]

7. de Melo, B.A.; Motta, F.L.; Santana, M.H. Humic acids: Structural properties and multiple functionalities for novel technological developments. Mater. Sci. Eng. C Mater. Biol. Appl. 2016, 62, 967-974. [CrossRef] [PubMed]

8. Trckova, M.; Matlova, L.; Hudcova, H.; Martin, F.; Zraly, Z.; Dvorska, L.; Beran, V.; Pavlik, I. Peat as a feed supplement for animals: A review. Vet. Med.Czech. 2005, 50, 361-377. [CrossRef]

9. Pukalchik, M.; Kydralieva, K.; Yakimenko, O.; Fedoseeva, E.; Terekhova, V. Outlining the Potential Role of Humic Products in Modifying Biological Properties of the Soil-A Review. Front. Environ. Sci. 2019, 7, 10. [CrossRef]

10. Gašparovič, M.; Hrnčár, C.; Gálik, B. The effect of feed additives in pheasants fattening: A review. J. Cent. Eur. Agric. 2017, 18, 749-761. [CrossRef] 
11. Pandey, A.K.; Pandey, S.D.; Misra, V.; Devi, S. Role of humic acid entrapped calcium alginate beads in removal of heavy metals. J. Hazard. Mater. 2003, 98, 177-181. [CrossRef]

12. Wang, S.; Zhang, Z.; Yin, X.; Wang, N.; Chen, D. Influences of Nitrogen Application Levels on Properties of Humic Acids in Chernozem Amended with Different Types of Organic Materials. Sustainability 2019, 11, 5405. [CrossRef]

13. Plyatsuk, L.; Chernysh, Y.; Ablieieva, I.; Bataltsev, Y.; Vaskin, R.; Roy, I.; Yakhnenko, E.; Roubík, H. Modelling and development of technological processes for low rank coal bio-utilization on the example of brown coal. Fuel 2020, 267, 117298. [CrossRef]

14. Skripkina, T.S.; Bychkov, A.L.; Tikhova, V.D.; Lomovsky, O.I. Mechanochemical Solid-Phase Reactions of Humic Acids from Brown Coal with Sodium Percarbonate. Solid Fuel Chem. 2018, 52, 356-360. [CrossRef]

15. Acharya, B.; Sule, I.; Dutta, A. A review on advances of torrefaction technologies for biomass processing. Biomass Convers. Biorefin. 2012, 2, 349-369. [CrossRef]

16. Davis, W.M.; Erickson, C.L.; Johnston, C.T.; Delfino, J.J.; Porter, J.E. Quantitative Fourier Transform Infrared spectroscopic investigation humic substance functional group composition. Chemosphere 1999, 38, 2913-2928. [CrossRef]

17. Tanaka, T.; Nagao, S.; Ogawa, H. Attenuated Total Reflection Fourier Transform Infrared (ATR-FTIR) Spectroscopy of Functional Groups of Humic Acid Dissolving in Aqueous Solution. Anal. Sci. Suppl. 2002, 17icas, i1081-i1084. [CrossRef]

18. Tatzber, M.; Stemmer, M.; Spiegel, H.; Katzlberger, C.; Haberhauer, G.; Mentler, A.; Gerzabek, M.H. FTIR-spectroscopic characterization of humic acids and humin fractions obtained by advanced $\mathrm{NaOH}, \mathrm{Na}_{4} \mathrm{P}_{2} \mathrm{O}_{7}$, and $\mathrm{Na}_{2} \mathrm{CO}_{3}$ extraction procedures. J. Plant. Nutr. Soil Sci. 2007, 170, 522-529. [CrossRef]

19. Yuan, Y.; Cai, X.; Tan, B.; Zhou, S.; Xing, B. Molecular insights into reversible redox sites in solid-phase humic substances as examined by electrochemical in situ FTIR and two-dimensional correlation spectroscopy. Chem. Geol. 2018, 494, 136-143. [CrossRef]

20. Baes, A.U.; Bloom, P.R. Diffuse Reflectance and Transmission Fourier Transform Infrared (DRIFT) Spectroscopy of Humic and Fulvic Acids. Soil Sci. Soc. Am. J. 1989, 53, 695-700. [CrossRef]

21. Vergnoux, A.; Guiliano, M.; Di Rocco, R.; Domeizel, M.; Théraulaz, F.; Doumenq, P. Quantitative and mid-infrared changes of humic substances from burned soils. Environ. Res. 2011, 111, 205-214. [CrossRef]

22. Karpukhina, E.; Mikheev, I.; Perminova, I.; Volkov, D.; Proskurnin, M. Rapid quantification of humic components in concentrated humate fertilizer solutions by FTIR spectroscopy. J. Soils Sed. 2018, 19, 2729-2739. [CrossRef]

23. Liu, X.Y.; Chen, W.; Qian, C.; Yu, H.Q. Interaction between Dissolved Organic Matter and Long-Chain Ionic Liquids: A Microstructural and Spectroscopic Correlation Study. Environ. Sci Technol. 2017, 51, 4812-4820. [CrossRef] [PubMed]

24. MacCarthy, P.; Mark, H.B.; Griffiths, P.R. Direct measurement of the infrared spectra of humic substances in water by Fourier transform infrared spectroscopy. J. Agric. Food Chem. 1975, 23, 600-602. [CrossRef]

25. Stevenson, F.J.; Goh, K.M. Infrared spectra of humic acids: Elimination of interference due to hygroscopic moisture and structural changes accompanying heating with KBr. Soil Sci. 1974, 117, 34-41. [CrossRef]

26. Katon, J.E.; Phillips, D.B. Infrared Spectroscopy at Subambient Temperatures. Appl. Spectrosc. Rev. 1973, 7, 1-45. [CrossRef]

27. Xu, B.; Mei, Y.; Xiao, Z.; Kang, Z.; Wang, R.; Sun, D. Monitoring thermally induced structural deformation and framework decomposition of ZIF-8 through in situ temperature dependent measurements. Phys. Chem. Chem. Phys. 2017, 19, 27178-27183. [CrossRef]

28. Verma, P.K.; Kundu, A.; Puretz, M.S.; Dhoonmoon, C.; Chegwidden, O.S.; Londergan, C.H.; Cho, M. The Bend+Libration Combination Band Is an Intrinsic, Collective, and Strongly Solute-Dependent Reporter on the Hydrogen Bonding Network of Liquid Water. J. Phys. Chem. B 2018, 122, 2587-2599. [CrossRef]

29. Koike, C.; Mutschke, H.; Suto, H.; Naoi, T.; Chihara, H.; Henning, T.; Jäger, C.; Tsuchiyama, A.; Dorschner, J.; Okuda, H. Temperature effects on the mid-and far-infrared spectra of olivine particles. Astron. Astrophys. 2006, 449, 583-596. [CrossRef]

30. Tielens, A.G.G.M.; Allamandola, L.J. Composition, Structure, and Chemistry of Interstellar Dust; Springer: Dordrecht, The Netherlands; pp. 397-470.

31. Plendl, J.N. Characteristic Energy Absorption Spectra of Solids; Springer: Boston, MA, USA, 1970; pp. 387-450.

32. Day, K.L. Temperature Dependence of Mid-Infrared Silicate Absorption. Astrophys. J. 1976, 203, L99. [CrossRef]

33. Zaikowski, A.; Knacke, R.F.; Porco, C.C. On the presence of phyllosilicate minerals in the interstellar grains. Astrophys. Space Sci. 1975, 35, 97-115. [CrossRef]

34. Mennella, V.; Brucato, J.R.; Colangeli, L.; Palumbo, P.; Rotundi, A.; Bussoletti, E. Temperature Dependence of the Absorption Coefficient of Cosmic Analog Grains in the Wavelength Range 20 Microns to 2 Millimeters. Astrophys. J. 1998, 496, $1058-1066$. [CrossRef]

35. Bowey, J.E.; Lee, C.; Tucker, C.; Hofmeister, A.M.; Ade, P.A.R.; Barlow, M.J. Temperature effects on the 15-85 $\mu$ m spectra of olivines and pyroxenes. Mon. Not. R. Astron. Soc. 2001, 325, 886-896. [CrossRef]

36. Johnston, C.T.; Kogel, J.E.; Bish, D.L.; Kogure, T.; Murray, H.H. Low-temperature Ftir Study of Kaolin-Group Minerals. Clays Clay Miner. 2008, 56, 470-485. [CrossRef]

37. Balan, E.; Delattre, S.; Roche, D.; Segalen, L.; Morin, G.; Guillaumet, M.; Blanchard, M.; Lazzeri, M.; Brouder, C.; Salje, E.K.H. Line-broadening effects in the powder infrared spectrum of apatite. Phys. Chem. Miner. 2011, 38, 111-122. [CrossRef]

38. Petrov, A.K.; Sechkarev, A.V. Temperature dependence of infrared spectra. Sov. Phys. J. 1965, 8, 62-64. [CrossRef]

39. Sirotiak, M.; Bartošová, A. Changes in Structure and Content Humic Substances in Soil During the Laboratory Simulated Fires. Trans. VSB 2016, 11, 42. [CrossRef] 
40. Nanda, S.; Reddy, S.N.; Hunter, H.N.; Butler, I.S.; Kozinski, J.A. Supercritical Water Gasification of Lactose as a Model Compound for Valorization of Dairy Industry Effluents. Ind. Eng. Chem. Res. 2015, 54, 9296-9306. [CrossRef]

41. Zuyi, T.; Shifang, L.; Jianjun, Z.; Fenling, S. Studies of Thermal Transformations of Humic and Fulvic Acids in Soils I. Infrared Spectroscopy and Temperature-Programmed Pyrolysis Mass Spectrometry. Chem. Ecol. 1997, 13, 237-248. [CrossRef]

42. Kolokassidou, C.; Pashalidis, I.; Costa, C.N.; Efstathiou, A.M.; Buckau, G. Thermal stability of solid and aqueous solutions of humic acid. Thermochim. Acta 2007, 454, 78-83. [CrossRef]

43. Malcolm, R.L.; MacCarthy, P. Limitations in the use of commercial humic acids in water and soil research. Environ. Sci. Technol. 1986, 20, 904-911. [CrossRef]

44. Nunn, S.; Nishikida, K. Advanced ATR Correction Algorithm. In Thermo Fisher Scientific Application Note 50581; Thermo Fisher Scientific: Madison WI, USA, 2008.

45. Baigorri, R.; Fuentes, M.; González-Gaitano, G.; García-Mina, J.M.; Almendros, G.; González-Vila, F.J. Complementary Multianalytical Approach To Study the Distinctive Structural Features of the Main Humic Fractions in Solution: Gray Humic Acid, Brown Humic Acid, and Fulvic Acid. J. Agric. Food Chem. 2009, 57, 3266-3272. [CrossRef]

46. Campanella, L.; Tomassetti, M.; Piccolo, A. Thermogravimetric and IR analysis of different extracts of humic substances. Thermochim. Acta 1990, 170, 67-80. [CrossRef]

47. Provenzano, M.R.; Senesi, N. Thermal Properties of Standard and Reference Humic Substances by Differential Scanning Calorimetry. J. Therm. Anal. Calorim. 1999, 57, 517-526. [CrossRef]

48. Provenzano, M.R.; Senesi, N.; Miikki, V. Characterization of Composts and Humic Acids from Pulp and Paper Mill Biosludges by DSC in Association with FT-IR Spectroscopy. J. Therm. Anal. Calorim. 1998, 52, 1037-1046. [CrossRef]

49. Janoš, P.; Kozler, J. Thermal stability of humic acids and some of their derivatives. Fuel 1995, 74, 708-713. [CrossRef]

50. Cihlár̆, Z.; Kucerik, J. Regenerated humic acids obtained by the air oxidation of south moravian lignite. part. 2. thermoanalytical characterization of products. Pet. Coal 2010, 52, 254-260.

51. Giovanela, M.; Parlanti, E.; Soriano-Sierra, E.J.; Soldi, M.S.; Sierra, M.M.D. Elemental compositions, FT-IR spectra and thermal behavior of sedimentary fulvic and humic acids from aquatic and terrestrial environments. Geochem. J. 2004, 38, 255-264. [CrossRef]

52. Rotaru, A.; Nicolaescu, I.; Rotaru, P.; Neaga, C. Thermal characterization of humic acids and other components of raw coal. J. Therm. Anal. Calorim. 2008, 92, 297-300. [CrossRef]

53. Sirbu, C.; Cioroianu, T.; Rotaru, P. About the humic acids and thermal behaviour of some humic acids. Ann. Univ. Craiova Phys. 2010, 20, 120-126.

54. Hoffmann, K.; Huculak-Maczka, M.; Grek, E. INVESTIGATION OF THE PROPERTY OF HUMIC ACIDS BY THERMAL ANALYSIS METHOD. Ecol. Chem. Eng. A 2013, 20, 261-269. [CrossRef]

55. Boguta, P.; Sokołowska, Z.; Skic, K. Use of thermal analysis coupled with differential scanning calorimetry, quadrupole mass spectrometry and infrared spectroscopy (TG-DSC-QMS-FTIR) to monitor chemical properties and thermal stability of fulvic and humic acids. PLoS ONE 2017, 12, e0189653. [CrossRef]

56. Larkin, P. Instrumentation and Sampling Methods. In Infrared and Raman Spectroscopy; Larkin, P., Ed.; Elsevier: Oxford, JD, USA, 2011; pp. 27-54. [CrossRef]

57. Laskina, O.; Young, M.A.; Kleiber, P.D.; Grassian, V.H. Infrared Optical Constants of Organic Aerosols: Organic Acids and Model Humic-Like Substances (HULIS). Aerosol Sci. Technol. 2014, 48, 630-637. [CrossRef]

58. Dinar, E.; Abo Riziq, A.; Spindler, C.; Erlick, C.; Kiss, G.; Rudich, Y. The complex refractive index of atmospheric and model humiclike substances (HULIS) retrieved by a cavity ring down aerosol spectrometer (CRD-AS). Faraday Discuss. 2008, 137, $279-295$. [CrossRef]

59. Kwon, D.; Sovers, M.J.; Grassian, V.H.; Kleiber, P.D.; Young, M.A. Optical Properties of Humic Material Standards: Solution Phase and Aerosol Measurements. ACS Earth Space Chem. 2018, 2, 1102-1111. [CrossRef]

60. Russell, J.D.; Fraser, A.R. Infrared methods. In Clay Mineralogy: Spectroscopic and Chemical Determinative Methods; Wilson, M.J., Ed.; Springer: Dordrecht, The Netherlands, 1994; pp. 11-67.

61. Madejová, J.; Komadel, P. Baseline studies of the clay minerals society source clays: Infrared methods. Clays Clay Miner. 2001, 49, 410-432. [CrossRef]

62. Senesi, N.; D'Orazio, V.; Ricca, G. Humic acids in the first generation of EUROSOILS. Geoderma 2003, 116, 325-344. [CrossRef]

63. Dhillon, G.S.; Gillespie, A.; Peak, D.; Van Rees, K.C.J. Spectroscopic investigation of soil organic matter composition for shelterbelt agroforestry systems. Geoderma 2017, 298, 1-13. [CrossRef]

64. Lucas, S.; Tognonvi, M.T.; Gelet, J.L.; Soro, J.; Rossignol, S. Interactions between silica sand and sodium silicate solution during consolidation process. J. Non-Cryst. Solids 2011, 357, 1310-1318. [CrossRef]

65. Lønstad Bleken, B.-T.; Mino, L.; Giordanino, F.; Beato, P.; Svelle, S.; Lillerud, K.P.; Bordiga, S. Probing the surface of nanosheet H-ZSM-5 with FTIR spectroscopy. Phys. Chem. Chem. Phys. 2013, 15, 13363-13370. [CrossRef] [PubMed]

66. De Benedetto, G.E.; Laviano, R.; Sabbatini, L.; Zambonin, P.G. Infrared spectroscopy in the mineralogical characterization of ancient pottery. J. Cult. Herit. 2002, 3, 177-186. [CrossRef]

67. Roeges, N.P.G. A Guide to the Complete Interpretation of Infrared Spectral of Organic Structures; Wiley: Hoboken, NJ, USA, 1994.

68. Nakamoto, K. Infrared and Raman Spectra of Inorganic and Coordination Compounds, Part A: Theory and Applications in Inorganic Chemistry; Wiley: Hoboken, NJ, USA, 2008. 
69. Workman, J. The Handbook of Organic Compounds, Three-Volume Set: NIR, IR, R, and UV-Vis Spectra Featuring Polymers and Surfactants; Elsevier Science: Amsterdam, The Netherlands, 2000.

70. Frost, R.L.; Vassallo, A.M. The Dehydroxylation of the Kaolinite Clay Minerals using Infrared Emission Spectroscopy. Clays Clay Miner. 1996, 44, 635-651. [CrossRef]

71. Ma, F.; Zeng, Y.; Du, C.; Shen, Y.; Ma, H.; Xu, S.; Zhou, J. Soil variability description using Fourier transform mid-infrared photoacoustic spectroscopy coupling with RGB method. Catena 2017, 152, 190-197. [CrossRef]

72. Krivoshein, P.K.; Volkov, D.S.; Rogova, O.B.; Proskurnin, M.A. FTIR photoacoustic spectroscopy for identification and assessment of soil components: Chernozems and their size fractions. Photoacoustics 2020, 18, 100162. [CrossRef]

73. Maréchal, Y. The molecular structure of liquid water delivered by absorption spectroscopy in the whole IR region completed with thermodynamics data. J. Mol. Struct. 2011, 1004, 146-155. [CrossRef]

74. Coates, J. Interpretation of Infrared Spectra, A Practical Approach. In Encyclopedia of Analytical Chemistry; Meyers, R.A., McKelvy, M.L., Eds.; Wiley: Hoboken, NJ, USA, 2006; p. a5606. [CrossRef]

75. Bock, J.; Su, G.-J. Interpretation of the Infrared Spectra of Fused Silica. J. Am. Ceram. Soc. 1970, 53, 69-73. [CrossRef]

76. Vaculíková, L.; Plevová, E.; Vallová, S.; Koutník, I. Characterization and differentiation of kaolinites from selected czech deposits using infrared spectroscopy and differential thermal analysis. Acta Geodyn. Et Geomater. 2011, 8, $59-67$.

77. Inoue, A.; Watanabe, T. Infrared Spectra of Interstratified Illite/Smectite from Hydrothermally Altered Tuffs (Shinzan, Japan) and Diagenetic Bentonites (Kinnekulle, Sweden). Clay Sci. 1989, 7, 263-275. [CrossRef]

78. Wilson, M.J. Dissolution and formation of quartz in soil environments: A review. Soil Sci. Annu. 2020, 71, 99-110. [CrossRef]

79. Vettegren, V.I.; Sobolev, G.A.; Kireenkova, S.M.; Morozov, Y.A.; Smul'skaya, A.I.; Mamalimov, R.I.; Kulik, V.B. Effect of water on the $\alpha-\beta$ phase transition in a surface quartz layer. Phys. Sol. State 2014, 56, 1228-1233. [CrossRef]

80. Spitzer, W.G.; Kleinman, D.A. Infrared Lattice Bands of Quartz. Phys. Rev. 1961, 121, 1324-1335. [CrossRef]

81. Max, J.J.; Chapados, C. Isotope effects in liquid water by infrared spectroscopy. III. $\mathrm{H}_{2} \mathrm{O}$ and $\mathrm{D}_{2} \mathrm{O}$ spectra from 6000 to $0 \mathrm{~cm}^{-1}$. J. Chem. Phys. 2009, 131, 184505. [CrossRef]

82. Heaney, P.J.; Kronenberg, A.K.; Prewitt, C.T.; Gibbs, G.V. Chapter 4. Hydrogen Speciation and Chemical Weakening of Quartz. In Silica; De Gruyter: Berlin, Germany, 1994; pp. 123-176. [CrossRef]

83. Cabaniss, S.E.; McVey, I.F. Aqueous infrared carboxylate absorbances: Aliphatic monocarboxylates. Spectrochim. Acta Part. A Mol. Biomol. Spectrosc. 1995, 51, 2385-2395. [CrossRef]

84. Cabaniss, S.E.; Leenheer, J.A.; McVey, I.F. Aqueous infrared carboxylate absorbances: Aliphatic di-acids. Spectrochim. Acta Part. A Mol. Biomol. Spectrosc. 1998, 54, 449-458. [CrossRef]

85. Dunn, G.E.; McDonald, R.S. Infrared spectra of aqueous sodium benzoates and salicylates in the carboxyl-stretching region: Chelation in aqueous sodium salicylates. Can. J. Chem. 1969, 47, 4577-4588. [CrossRef]

86. Calderón, F.J.; Mikha, M.M.; Vigil, M.F.; Nielsen, D.C.; Benjamin, J.G.; Reeves, J.B. Diffuse-Reflectance Mid-infrared Spectral Properties of Soils under Alternative Crop Rotations in a Semi-arid Climate. Commun. Soil Sci. Plant. Anal. 2011, 42, 2143-2159. [CrossRef]

87. Nardi, S.; Ertani, A.; Francioso, O. Soil-root cross-talking: The role of humic substances. J. Plant. Nutr. Soil Sci. 2017, 180, 5-13. [CrossRef]

88. Bronnikov, S.V.; Vettegren, V.I.; Frenkel, S.Y. Description of thermal and mechanical properties of drawn polymers over a wide temperature range. Polym. Eng. Sci. 1992, 32, 1204-1208. [CrossRef]

89. Poulet, H.; Mathieu, J.P. Vibration Spectra and Symmetry of Crystals; Gordon and Breach: New York, NY, USA; London, UK; Paris, France, 1976

90. Scott, J.F.; Porto, S.P.S. Longitudinal and Transverse Optical Lattice Vibrations in Quartz. Phys. Rev. 1967, 161, 903-910. [CrossRef]

91. Tan, C.Z. Optical interference in overtones and combination bands in $\alpha$-quartz. J. Phys. Chem. Solids 2003, 64, 121-125. [CrossRef]

92. Zhuang, J.; Li, M.; Pu, Y.; Ragauskas, A.; Yoo, C. Observation of Potential Contaminants in Processed Biomass Using Fourier Transform Infrared Spectroscopy. Appl. Sci. 2020, 10, 4345. [CrossRef]

93. Palacios, E.G.; Juárez-López, G.; Monhemius, A.J. Infrared spectroscopy of metal carboxylates: II. Analysis of Fe(III), Ni and Zn carboxylate solutions. Hydrometallurgy 2004, 72, 139-148. [CrossRef]

94. Palacios, E.G.; Monhemius, A.J. Infrared spectroscopy of metal carboxylates: I. Determination of free acid in solution. Hydrometallurgy 2001, 62, 135-143. [CrossRef]

95. Herrera-Gómez, A.; Velázquez-Cruz, G.; Martín-Polo, M.O. Analysis of the water bound to a polymer matrix by infrared spectroscopy. J. Appl. Phys. 2001, 89, 5431-5437. [CrossRef]

96. Honghong, H.; Meifang, G.; Juan, L.; Ortín, A.; Yau, W.W. Analysis of Propylene-1-Butene Copolymer Composition by GPC with Online Detectors. Macromol. Symp. 2015, 356, 110-121. [CrossRef]

97. Yamagishi, H.; Nakashima, S.; Ito, Y. High temperature infrared spectra of hydrous microcrystalline quartz. Phys. Chem. Miner. 1997, 24, 66-74. [CrossRef]

98. Mikhaylova, Y.; Adam, G.; Häussler, L.; Eichhorn, K.J.; Voit, B. Temperature-dependent FTIR spectroscopic and thermoanalytic studies of hydrogen bonding of hydroxyl (phenolic group) terminated hyperbranched aromatic polyesters. J. Mol. Struct. 2006, 788, 80-88. [CrossRef]

99. Du, C.; Goyne, K.W.; Miles, R.J.; Zhou, J. A 1915-2011 microscale record of soil organic matter under wheat cultivation using FTIR-PAS depth-profiling. Agron. Sustain. Dev. 2013, 34, 803-811. [CrossRef] 
100. Kar, S.; Maity, J.P.; Jean, J.-S.; Liu, C.-C.; Nath, B.; Lee, Y.-C.; Bundschuh, J.; Chen, C.-Y.; Li, Z. Role of organic matter and humic substances in the binding and mobility of arsenic in a Gangetic aquifer. J. Environ. Sci. Health Part. A 2011, 46, 1231-1238. [CrossRef]

101. Volkov, D.S.; Krivoshein, P.K.; Mikheev, I.V.; Proskurnin, M.A. Pristine detonation nanodiamonds as regenerable adsorbents for metal cations. Diam. Relat. Mater. 2020, 110, 108121. [CrossRef]

102. Nguyen, T.; Janik, L.; Raupach, M. Diffuse reflectance infrared fourier transform (DRIFT) spectroscopy in soil studies. Soil Res. 1991, 29, 49-67. [CrossRef]

103. Fukuda, J.-i.; Shimizu, I. Water distribution in quartz schists of the Sanbagawa Metamorphic Belt, Japan: Infrared spectroscopic mapping and comparison of the calibrations proposed for determining water contents. Earth Planets Space 2019, 71, 136. [CrossRef]

104. Jiang, H.; Chen, B.-X.; Fu, C.-S.; Sui, G.-R.; Iso, M. gamma-irradiation damage of quartz fiber and its effects on near-infrared transmission characteristics. Acta Phys. Sin. 2010, 59, 7782-7787.

105. Hofmeister, A.M.; Bowey, J.E. Quantitative Infrared Spectra of Hydrosilicates and Related Minerals. Mon. Not. R. Astron. Soc. 2006, 367, 577-591. [CrossRef]

106. Shinoda, K.; Aikawa, N. Absorption coefficients of overtone and combination modes of quartz. Mineral. Mag. 1994, 58,601-606. [CrossRef] 